Document downloaded from:

http://hdl.handle.net/10251/39763

This paper must be cited as:

Furió Ferri, D.; González Gancedo, S.; Juan, M.; Seguí, I.; Rando, N. (2013). Evaluation of learning outcomes using an educational iPhone game vs. traditional game. Computers and Education. 64:1-23. doi:10.1016/j.compedu.2012.12.001.

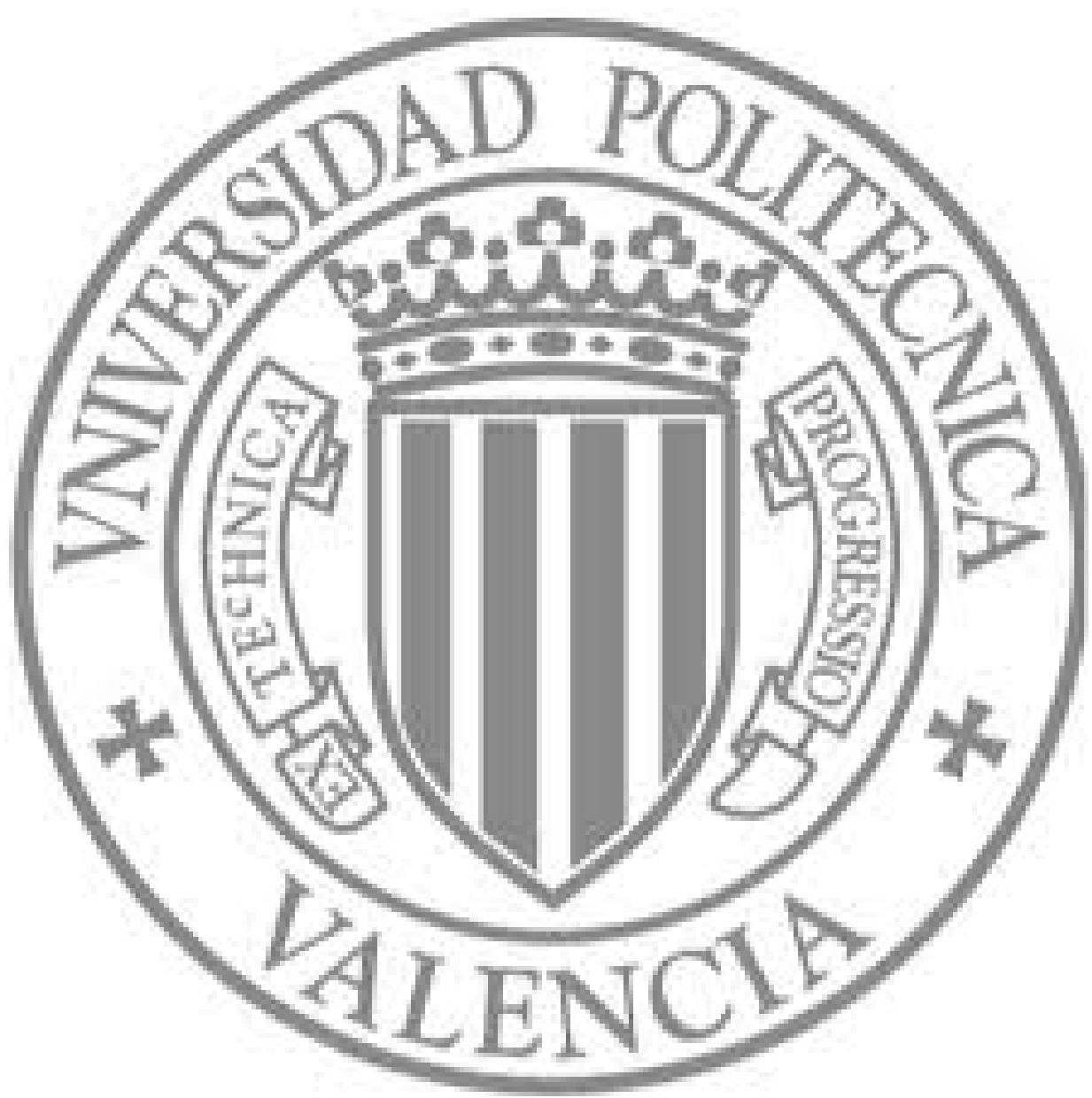

The final publication is available at

http://dx.doi.org/10.1016/j.compedu.2012.12.001

Copyright Elsevier 


\title{
Evaluation of learning outcomes using an educational iPhone game vs. traditional game
}

\author{
David Furió ${ }^{\mathrm{a}}$, Santiago González-Gancedo ${ }^{\mathrm{a}}$, M.-Carmen Juan ${ }^{\mathrm{a},{ }^{*}}$, Ignacio Seguí ${ }^{\mathrm{b}}$, Noemí Rando ${ }^{\mathrm{b}}$ \\ ${ }^{a}$ Instituto Universitario de Automática e Informática Industrial, Universitat Politècnica de València, \\ Camino de Vera, s/n. 46022 Valencia, Spain \\ ${ }^{\mathrm{b}}$ AIJU, Ibi, Alicante, Spain
}

\begin{abstract}
In this paper, we present an initial study to determine the subject preferences for educational computer games for children, in which 150 education professionals participated. From the results of this first study, we have developed an iPhone game for transmitting knowledge as part of multiculturalism, solidarity and tolerance following established learning theories, several design principles, and the objectives and competences of the Spanish law for primary education. We also report on a second study to determine whether the iPhone game has better learning outcomes than a traditional game by analyzing the participation of 84 children ranging in age from 8 to 10 years old. The frequency of playing with consoles or computer games was also taken into account in this second study, and the worldwide trend of previous studies has been corroborated. For learning outcomes, the results did not show significant differences between the two groups. However, $96 \%$ of the children indicated that they would like to play with the iPhone game again, and $90 \%$ indicated that they preferred the experience with the iPhone game over the traditional one. From these results, we can conclude that the children achieved similar knowledge improvements using both the autonomous game (iPhone game) and the custom, guided game (traditional game). This could facilitate versatility in the learning process since the learning activity could be performed at any place and time without requiring supervision. Therefore, it could be a useful tool in the learning process and help teachers to fulfill students' training needs.
\end{abstract}

Keywords: Game-based learning, m-learning, Augmented Reality, iPhone game, learning outcomes

\section{Introduction}

\subsection{Net generation}

There is a growing belief that students and learning methods are changing. Students today have grown up in a different generation than their parents. They have grown up with computer games and other technologies that have changed their preferred leisure styles, their social interaction, and even their learning preferences (Bekebrede, Warmelink \& Mayer, 2011). Since children are accustomed to the daily use of technology such as computers, mobile devices, consoles, etc., this generation is commonly referred to as the 'gamer generation' (Beck \& Wade, 2004, 2006), 'digital natives' (Prensky, 2001a), or the 'net generation' (Tapscott, 1998). Prensky pointed out that these 'digital natives' have experienced 'mind alterations' and 'cognitive change' (2001a, p. 39). Beck and Wade highlighted the fact that the 'gamer generation' has 'systematically different ways of working' that are the consequence of 'one central factor: growing up with video games' (Beck \& Wade, 2004, 2006, p. 2). Tapscott argued that the 'net generation' 'are learning, playing, communicating, working and creating communities very different than their parents' (Tapscott, 1998, p. 2, quoted in Prensky, 2001a, p. 39). It is also widely accepted that this new style of learning requires new ways of teaching. Cognitive changes of digital natives make it difficult to keep within the zone of proximal development (Vygostky, 1978) when using the learning methods of their parents. They require new motivations that capture and hold their attention, engaging them in the learning process when they are in a state of flow (Csikszentmihalyi, 1990). 


\subsection{Game-Based Learning}

Game-based learning (GBL) is thought to be an effective tool for learning (Kebritchi \& Hirumi, 2008; Papastergiou, 2009) that can promote enhanced learning experiences (Connolly, Stansfield, and Hainey, 2007) and student motivation (Papastergiou, 2009). According to Connolly, Stansfield, and Hainey (2007), GBL can be defined as "the use of a computer game-based approach to deliver, support, and enhance teaching, learning, assessment, and evaluation". There is also widespread acknowledgement of the advantages that the use of games has in elementary and secondary education (Ebner \& Holzinger, 2007). Kebritchi \& Hirumi (2008) identified the following five reasons for defining GBL as an effective tool for learning: 1) GBL uses action instead of explanation; 2) GBL creates personal motivation and satisfaction; 3) GBL accommodates multiple learning styles and skills; 4) GBL reinforces mastery of skills; and 5) GBL provides an interactive and decision-making context. Computer games not only integrate knowing and doing, but they also "bring together ways of knowing, ways of doing, ways of being, and ways of caring: the situated understandings, effective social practices, powerful identities, and shared values that make someone an expert" (Shaffer, Squire, Halverson, and Gee, 2004). According to O'Neil, Wainess and Baker (2005), computer games are useful for instructional purposes and they also provide multiple benefits: (a) complex and diverse approaches to learning processes and outcomes; (b) interactivity; (c) ability to address cognitive as well as affective learning issues; and (d) motivation for learning. Robertson \& Howells (2008) considered that computer games could develop a number of cognitive skills. Moreover, game-playing activity is linked with the possibility of developing skills in decision-making, design, strategy, cooperation, and problem solving (McFarlane, Sparrowhawk, \& Heald, 2002; Ebner \& Holzinger, 2007). Students use games to explore, discover, and question. These "learning by doing" and "active learning" concepts are important principles, which underlie GBL (Yang, 2012).

In the last few years, the use of mobile devices as platforms for GBL offers new options for providing better learning experiences. Mobile devices could change how students behave and interact with each other (Motiwalla, 2007). M-learning is a new learning paradigm that exploits the use of mobile devices in education (Sharples, Corlett, \&Westmancott, 2002). Jones and Jo (2004) added that $\mathrm{m}$-learning includes the concept of anytime/anywhere. M-learning systems can be an ideal platform for GBL because these systems can improve lifelong learning and can provide more versatile educational methods (Lavín-Mera, Moreno-Ger \& Fernández-Manjón, 2008). The extended use of portable gaming platforms among young people makes mobile GBL truly relevant because some idle moments can be taken as an opportunity for learning (Virvou, \& Alepis, 2005). Apart from allowing users to access the videogame anytime and anywhere, mobile GBL also improves m-learning scenarios and offers additional value to the educational advantages of GBL (Lavín-Mera, et al., 2008). If all of these benefits and technologies are considered, educators can incorporate powerful tools into their teaching activities that can enrich and complement children's skills through play.

Governments have considered this potential, and they are funding educational game research and development projects (GATE, 2011; Mayer, Bekebrede, Stegers-Jager, 2007; Programmabureau Maatschappelijke Sectoren \& ICT, 2011; Warmelink \& Mayer, 2009). The Spanish government is not an exception and is funding several research projects (e.g. APRENDRA). Moreover, the Spanish Education Law considers play to be a basic need. Due to its motivational aspect, play is considered to be an ideal resource for use at school for showing overall content of the subject matter and is also considered to be the link for significant learning. The Spanish government understands the need for developing a varied and exciting range of games that provide multiple learning opportunities and introducing them into schools. The game is contemplated as a methodology for different models of education, being put into practice in both formal and non-formal education. 


\subsection{Augmented Reality}

In this subsection, only a definition of AR and some advantages that AR offers are introduced. In section 1.5, AR systems that are related to our work are cited in more detail.

One of the technologies that is being incorporated in many fields is Augmented Reality (AR). AR allows the user to see the real world, with virtual objects superimposed upon the real world that supplement reality. In an ideal AR application, the real and virtual objects would appear that coexist in the same space. A common accepted definition of AR defines it as a system that has these three features (Azuma, 1997):

1) It combines real and virtual objects;

2) It has real-time interaction; and

3) It has 3-D registration.

Milgram and Kishino (1994) defined the virtuality continuum (Figure 1) as a scale that ranges from the completely real to the completely virtual environment including AR and Augmented Virtuality (AV). Mixed Reality is the area between the completely real and the completely virtual elements and includes both AR and AV. Therefore, MR can be used to refer to any combination of real and virtual elements. AR is most suitable when this combination is closer to the real environment, that is, the scene is mainly real. In contrast, AV is commonly used when this combination is closer to the virtual environment, that is, the scene is mainly virtual.

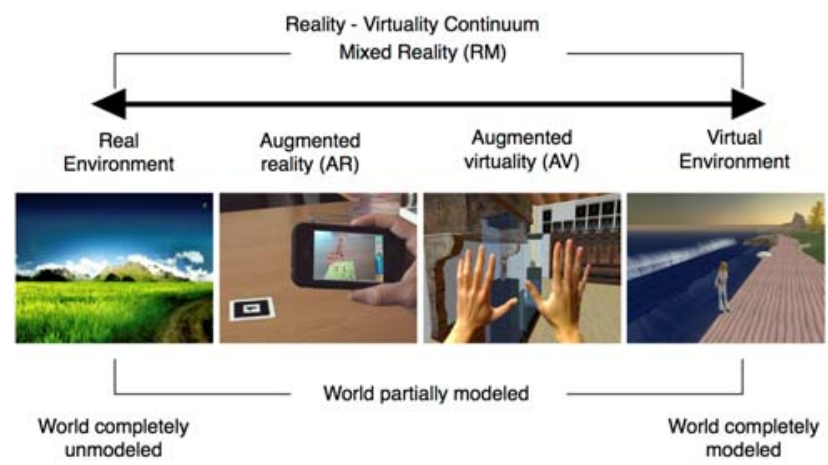

Fig. 1. Representation of the virtuality continuum.

AR systems can use one or more of the following technologies: digital cameras, optical sensors, accelerometers, GPS, etc. The iPhone presents a combination of some of these elements, making it a suitable platform for AR. AR systems have a lot of applications due to the enhancement of the user's perception and the fact that the user can interact with the real world using virtual objects.

Fields like medicine, entertainment, education or navigation, among others have made use of the AR technology (Krevelen \& Poelman, 2010). Some advantages that AR offers are:

1) Smooth transitions between reality and virtuality; the use of a tangible interface metaphor that uses physical objects to manipulate virtual elements.

2) Participants can interact between real and virtual environments, which is something that cannot be done in virtual environments.

3) Users do not have to use their imagination to envision what is happening. They can see it.

\subsection{New methods vs. traditional method}

A critical aspect in the evaluation of new methods is to determine the best method to compare with. The aim of this comparison is to demonstrate that the new method is at least as good as the one already in use in relation to the different aspects evaluated. The evaluation of several aspects of GBL is very important. Due to the multidimensionality of learning with GBL, a number of technical, orientational, affective, cognitive, pedagogical, and other aspects should be considered in its evaluation (Lewin, 1995). The technical aspect examines usability issues regarding interface, physical problems, and system hardware and software. The orientation aspect focuses on the relationship of the user and the 
augmented environment; it includes navigation, spatial orientation, presence and immersion, and feedback issues. The affective parameter evaluates the user's engagement, likes and dislikes, and confidence in the system. The cognitive aspect identifies any improvement of the subject's internal concepts through this learning experience. Finally, the pedagogical aspect concerns the teaching approach: how to gain knowledge effectively about the environment and the concepts that are being taught. Until now, many computer games have been developed for learning purposes, but very few perform a thorough analysis as several researchers have pointed out (Connolly, Stansfield, \& Hainey et al., 2007; de Freitas, 2006; O’Neil et al. 2005; Squire, 2002). There is also a lack of comparison of the effectiveness of computer games with other learning methods such as lectures (Leemkuil, 2005).

Another aspect pointed out by researchers is the development of educational computer games with no coherent theory of learning or underlying body of research (Shaffer et al., 2004). In our work, the main aspect to check was the learning outcomes. Reviewing previous work, comparing new methods with traditional methods seems to be a common technique (Randel et al., 1992; Rosas et al., 2003; Ebner and Holzinger, 2007; Telner et al., 2010; Yang, 2012; Chen and Tsai, 2012). Following this trend, we compared our proposal with traditional games. Randel et al. (1992) reviewed the literature that compared the instructional effectiveness of games to conventional classroom instruction. Studies dealing with empirical research rather than teachers' judgments were reviewed. Published reviews of research in English dating from 1963 to 1984 were examined and the literature was searched for studies from 1984 to 1991 . Of the 68 studies considered over a period of 28 years, 38 show no difference between games and conventional instruction; 22 favor games; 5 favor games, but how their controls were played were questionable; and 3 favor conventional instruction. Rosas et al. (2003) presented a software application that contained 5 games with the objective of evaluating the effects of video-games on students' language acquisition skills and mathematical operations. They designed a tool similar to Nintendo's Gameboy for the trials. The 1274 students that participated in the research study were divided into three groups: Experimental Group (EG), composed of 758 children; Internal Control (IC), composed of 347 students; and External Control (EC) composed of 169 participants. The games were compared with a traditional classroom environment. For example, one of the games was called Hermes. In this game, the children had to throw magic towards the correct flying blocks to form a bridge. The children of the EG learned new vocabulary and numeric sequences while playing. The children that pertained to the IC and EC learned the same through a school lesson. Pretests and posttests were used to evaluate the learning outcomes. The results regarding the acquired knowledge showed significant differences in favor of the students in schools were the experimental tool was introduced (EG and IC). Ebner and Holzinger (2007) designed an online computer game for teaching civil engineering to university students. In the game, the students had to calculate the internal forces of a system. Three possible answers were presented to the players with only one correct solution. The learners had to select the correct answers within the available time. The game was compared with a traditional school lesson. The 121 students that took part in the trials were divided into three groups: the students who attended the lectures/courses and played the game on a voluntary basis; the students who attended the lectures/courses and did not play the game; and the online participants who only played the game. A pretest and a posttest were used to evaluate the learning outcomes. The results showed that the people who played the game achieved the same learning results as the people who used the traditional method. Telner et al. (2010) evaluated family physicians' enjoyment of and knowledge gained from GBL, compared with traditional case-based learning, in a continuing medical education event on stroke prevention and management. The game was based on the board game "Snakes and Ladders". Twenty-two multiple-choice and true-or-false questions were developed from materials adapted from a nationally accredited educational workshop. Each game involved 1 trained moderator, who facilitated the game, kept time, and had the answers to the game's questions and 3 teams (pairs) of physicians. Thirty-two family physicians and 3 senior family medicine residents participated in the study. They were divided into two groups: case-based and game-based. An immediate posttest and later a three-month later posttest were used to evaluate the enjoyment and 
knowledge gained. The results about knowledge showed no significant difference in scoring between the groups. The participants in the game-based group reported higher levels of satisfaction with the learning experience. Yang (2012) investigated the effectiveness of digital GBL on students' problem solving, learning motivation, and academic achievement in a civics and society course. Forty-four students between the ages of 15 and 16 years old participated in the study. The students were divided into two groups: a control group that used lectures, and an experimental group that used commercial games. The study lasted 22 weeks where the children carried out multiple activities. For example, during weeks 2-11, the study adopted daily economics as the instructional content. The instructor used Tycoon City: New York!, which is a virtual city-building game where players are responsible for developing New York City. Each week, the instructor stated the gaming tasks and provided the students with basic instruction related to daily economics. Meanwhile, the control group learned the same concepts through lectures and worksheets. The results of the study showed that digital GBL was clearly effective in promoting students' problem-solving skills, while the control group showed no improvement. Digital GBL also motivated more of the students than the control group. No significant differences were found with regard to academic achievement. Chen and Tsai (2012) developed an augmented reality library instruction system (ARLIS) to teach users how to use library resources effectively. ARLIS integrated Augmented Reality (AR) and interactive 3D technologies, providing a library instruction mode in a real library environment. They carried out a study with the aim of enhancing interest in learning the Chinese library classification scheme and enhancing library instruction performance using the situational learning approach supported by AR techniques that can be connected to a real library environment. A total of 116 students participated in the experiment. They were divided into two groups: the experimental group that used ARLIS, and the control group that did not use ARLIS or any computer-assisted instruction system (conventional librarian instruction). Four pretests and four posttests were used to evaluate the learning gain obtained after performing the trials. Both groups performed the same library instruction activities. The results showed that the learning performance was improved significantly independently of the method used, but no significant differences were found between ARLIS and conventional librarian instruction. The results also showed that there were no gender differences in learning performance between the proposed ARLIS and conventional librarian instruction.

The comparison of traditional methods with new methods has also been used for physical activity (Vernadakis et al. 2012; Brumels et al., 2008). Vernadakis et al. (2012) presented a study comparison between a Nintendo Wii with Wii Fit Plus and a more traditional approach in order to determine whether or not there is a difference between an exergame-based balance training program and a traditional one. Thirty-two students between the ages of 20 and 22 years old participated in the trials. The students were divided into two groups: The Nintendo Wii group, which used the interactive games Wii Fit Plus of the Nintendo Wii console; and the traditional group, which used an exercise program with mini trampoline and inflatable discs. A pretest and a posttest were used to determine the gain of balance ability. The two training program groups performed a specific balance program for 8 weeks. The results showed that both groups had an improvement in the balance ability. Brumels et al. (2008) carried out a research study to compare the efficacy of traditional and video game-based balance programs in improving balance performance measurements and compliance. Three methods were compared. The two videogames used Dance Dance Revolution (DDR) and Wii. The DDR program allowed participants the opportunity to play DDR games using one foot. During play, in a standing position, the player had to respond to a series of arrows that continually scroll on the television screen (pointing left, right, up, or down), by moving their non-weight bearing foot and touching the corresponding arrow on the game mat. The Wii Program used Wii Fit and consisted of doing the balance training exercises created by the Nintendo Corporation. The Traditional Balance Program consisted of the Star Excursion Balance Tests and single leg force plate balancing data. Twenty-five participants between the ages of 18 and 24 participated in the study. They were divided into four groups: a control group, which only participated in the pre- and post-testing sessions; and the three 
exercise groups (traditional, DDR, or Wii FitTM). Pretests and posttests were used to evaluate the improvements in balance performance. The results of the study showed that postural sway reduction and average deviation on the y-axis was observed in the DDR trained group, and that average deviation improvements were noted in the Wii Fit trained group. The traditional balance program significantly improved two of the three tested Star Excursion Balance activities. The results also showed that videogame-based balance programs were less difficult and more engaging and enjoyable than the traditional program exercises.

There are scenarios where paper-based methods could be chosen as a good alternative. For example, when the activity or learning experience can be autonomous without requiring monitoring by people (Ruchter, Klar and Geiger, 2010; Hainey, Connolly, Stansfield and Boyle, 2011) or for the evaluation of acquired knowledge (McDonald, 2002). Ruchter, Klar and Geiger (2010) developed an environmental education application called MobiNaG for a guided nature tour. Seventy-six adults and 185 children participated in the study. They were divided into three groups: the first group was guided by the MobiNaG prototype; the second group used a paper-based guidebook; and the third group was guided by a person. A pretest and a posttest were used to evaluate the knowledge, attitude, values, and concerns as well as behavioral intention/behavior. The group using the textbook relied on the map and the pictures of the respective trees. The group using the mobile guide system was notified by an audio signal upon arrival, accompanied by a message box announcing the station and allowing the user to view more detailed location-based information. The results of the study showed significant knowledge gain for children as well as adults and significant changes in attitude and behavior scores for the adult participants (independent of the method used). Hainey, Connolly, Stansfield and Boyle (2011) presented a game about software engineering education, the basic idea of which was to manage and deliver a number of software development projects. In the game, each player had a specific role, such as project manager, systems analyst, systems designer, or team leader. The player assigned to the system analyst role had to identify the requirements for the project. To do this, the player had to move through the game and 'talk' to the non-player characters in the game. The analyst produced an initial 'wishlist' of requirements. Then, the project manager had two choices: send the requirements to the designer or consider the requirements to be incorrect and ask the analyst to rework the requirements. The game was compared with two traditional approaches: role-play, where members of staff and students acted out the parts of the characters in the game using the exact same case study and script that was incorporated into the game; and paper-based, where the participants were presented with the same summary information excluding game and role-play elements. Ninety-two students took part in the study. They were divided into three groups: the experimental group (game) and the control groups (paper-based and role-play). A pretest and a posttest were used to evaluate the acquired knowledge. The results of the research showed that the game was as effective as the role-playing method and more effective than the paper-based case studies.

\subsection{Motivation and Objectives}

In this paper, we present an iPhone game that includes AR. However, it is not just an AR game; it combines AR with video games. We decided to use AR because, according to previous research, AR motivates and engages the users (Kerawalla, Luckin, Seljeflot \& Woolard, 2006) and makes a good impression on those who have used it (Ardito, 2007). AR is a powerful and engaging experience (Shelton, 2004), and can be a great and innovative way of teaching lessons to students since, with AR, players can interact with real and virtual objects, which cannot be done in virtual environments. We also decided to use AR because there are few mobile learning games that use this technology. As the innovative aspect is the AR, in the rest of this section, we cite a few AR systems that were developed previously for learning. For desktop computers, there are different subjects that can be studied: volcanoes (Woods et al., 2004); dinosaurs (Bimber et al., 2001); the relation between the earth and the sun (Shelton \& Hedley, 2002); mathematics and geometry (Kaufmann, 2004); how to play billiards (Larsen et al., 2005); organic chemistry (Fjeld et al., 2007); the interior of the human body (Juan et al., 
2008); or endangered animals (Juan et al., 2010, 2011a). For handheld devices, several educational AR applications have also been presented for learning different subjects: heritage temples (Wang et al., 2009); math and literacy skills (O'Shea et al., 2009); or how to recycle (Juan et al., 2011b). For the iPhone, several applications have also been developed: identifying mountains (Karpischek et al., 2009); or cooking (Koh et al., 2010).

We decided to use an iPhone because when we initiated this research study, the iPhone was one of the most advanced and powerful smartphones on the market, and still continues to be a good one. It provides high graphics capabilities and has an integrated camera, which is needed for AR applications. The iPhone has sensors (like a multi-touch screen or an accelerometer) that can be used to make more intuitive interaction with AR applications or to add features that are not possible with other systems or devices (Rosler, 2009). For example, with multi-touch screens, the users can move virtual objects by tapping on them and dragging them (Rosler, 2009). The built-in accelerometer can detect the inclination angle of the device, which allows the users to interact in a new way with the application by simply tilting the device. Another reason why we used the iPhone was because it is becoming one of the most used smartphones in the world. Butler (2011), and West and Mace (2010) estimated that the iPhone got into the number two position in the US market share, with a $26 \%-28 \%$ of the total share. According to Butler (2011), the iPhone market share grew by $61 \%$ from the second quarter to the third quarter 2010.

The main objectives of this study were to determine if the game helped children in the learning process and to check which game (the iPhone game or the traditional game) had more influence on the participants regarding acquired knowledge and satisfaction. The primary hypothesis was that playing the iPhone game would lead to at least equivalent learning results as the traditional game and that children would prefer the iPhone game. One of the reasons on which we base our hypothesis is the fact that children belong to the 'gamer generation' (they are accustomed to the use of technology). To prove this hypothesis, we used questionnaires and observations that were designed by the people in charge of the trials. To test the primary hypothesis, we evaluated the quantitative data obtained from the questionnaires using t-tests and ANOVAs.

The reasons why we conducted this study were the following:

1) There is little experience in the use of mobile GBL (Lavín-Mera, Moreno-Ger \& FernándezManjón, 2008).

2) Few works have used formal educational learning theories for developing learning games. One important difference with other research work is that, in our study, apart from developing content that is related to the school curricula, we also took into consideration two formal educational learning theories in order to improve our game effectiveness with regard to learning.

3) AR has not been exploited for mobile learning games.

4) Unlike other research works, we performed a preliminary study (see Section 2) to take into consideration the opinions and preferences of professionals in education when designing our game. In our case, the results of this preliminary study were one of the three reasons for choosing the theme and the type of game (the three reasons for choosing the theme and the type of game are explained in more detail in Section 3.3).

5) Other works have compared new methods with traditional lessons. We propose an AR game and compare it with a traditional game.

The paper is organized as follows. Section 2 focuses on the preliminary study carried out to determine the subject preferences for educational computer games. Section 3 describes the iPhone game, the underlying learning theories, the design principles, and the technical features. Section 4 presents the study, and Section 5 presents the results. In Section 6, we proceed with the discussion. Finally, in Section 7, we present our conclusions, and future work. 


\section{Preliminary study}

A preliminary study was carried out to determine the subject preferences for an educational computer game for children ranging in age from 8 to 10 years old. Professionals in education participated in this study. These professionals were: primary and secondary school teachers, higher education teachers, vocational studies teachers, university teachers, and other education professionals (pedagogues, educational psychologists, etc.). The objectives were the following:

- To know the opinion of education professionals about the role those new technologies can play in this field.

- To identify the most appropriate type of game for application in educational games.

- To identify the most appropriate subjects for application in educational games.

- To know the professionals' knowledge about AR.

The study was designed to reflect the opinions of a large community of professionals from the whole country, and, therefore, the method chosen to gather the data was an anonymous electronic survey. The questions in this survey were designed and refined by a smaller set of experts in education who were required to attend a focus group session in person. In that session, they discussed the type of questions that should be included in the survey and the kinds of answers they preferred to have (in this case, Likert scales instead of open answers). Thirteen experts participated in the focus group, and it should be pointed out that they did not participate in the survey.

A total of 150 professionals participated in the survey (68\% females and $32 \%$ males). Most of the participants $(68 \%)$ have been practicing for more than 10 years; $24 \%$ had educational experience of between 5 and 10 years; and only 8\% reported educational experience of less than 5 years. Figure 2 shows the professional context of the participants. As can be observed, $33.33 \%$ of the participants were pedagogues or educational psychologists, and $30 \%$ of the participants were primary school teachers.

A questionnaire was used to collect the data (Table 1). The questionnaire contained questions related to the use of new technologies, knowledge about AR, and subject preferences.

For the question regarding the use of new technologies (Table 1, QP1), most of the participants $(66.67 \%)$ considered that the new technologies were quite useful, given a score of $2 ; 30 \%$ of the participants gave a score of 1 (very); $3.33 \%$ of the participants gave a score of 3 (somewhat); and none of the participants gave a score of 4 (a little bit) or 5 (not at all).

There were three questions regarding subject preferences. Figure 3 shows the percentages for each score for the first question (Table 1, QP2). The most appreciated type of game was the game that requires skills. Figure 4 shows the scores for the last question (Table 1, QP3). Each participant chose 4 subjects: $63 \%$ chose 'multiculturalism, solidarity, and tolerance'; and $63 \%$ chose 'nature and living organisms'.

There was also a question regarding their knowledge about AR: $26 \%$ where familiar with the characteristics of this technology, 53.3\% had heard about it, and $20.67 \%$ had not heard of it. This result motivated the pilot study presented in this paper to a large extent because even though the vast majority of the professionals considered new technologies to be useful or very useful, not many of them were aware of the benefits of AR.

Table 1. Preliminary study questions

QP1 Do you think that new technologies could be useful tools for use in the classroom?, 1) very, 2) quite a bit, 3) somewhat, 4) a little bit, 5) not at all.

QP2 As an education professional, what type of game do you prefer third- and fourth-grade primary school students to play? Mark the option or options that you prefer: 1) symbolic, 2) construction, 3) strategy, 4) questions, 5) movement, 6) skill, 7) do not know / no answer, 8) other (specify).

QP3 Please indicate 4 subjects that you would like to be included in a learning game: 1) nature and living organisms; 2) science and technology; 3) traffic rules; 4) sport and outdoor activities; 5) health and hygiene; 6) moral and ethical values; 7) multiculturalism, solidarity, and tolerance; 8) calculation and reasoning; 9) music; 10) history; 11) language and understanding; 12) other (specify). 


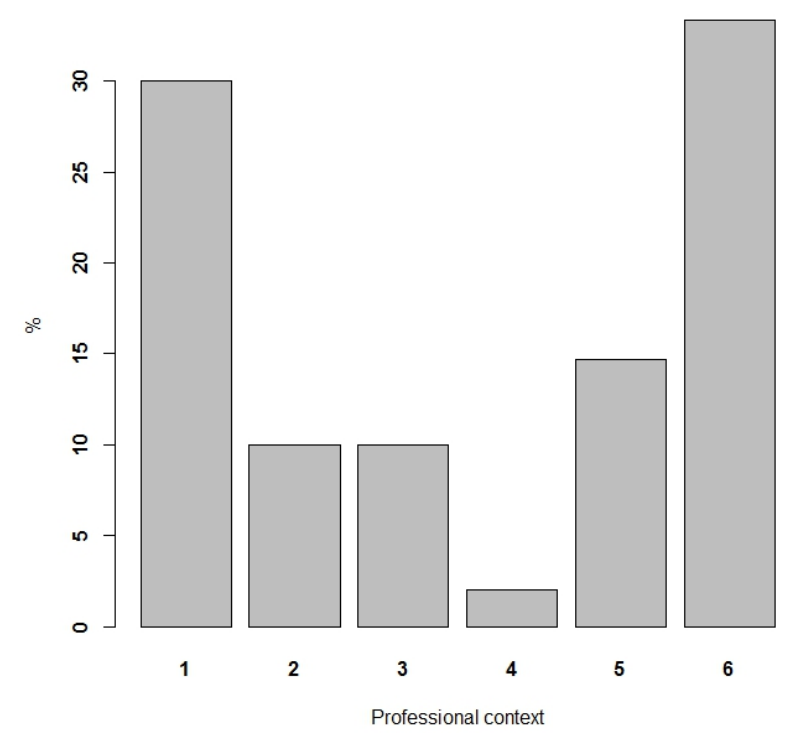

Fig. 2

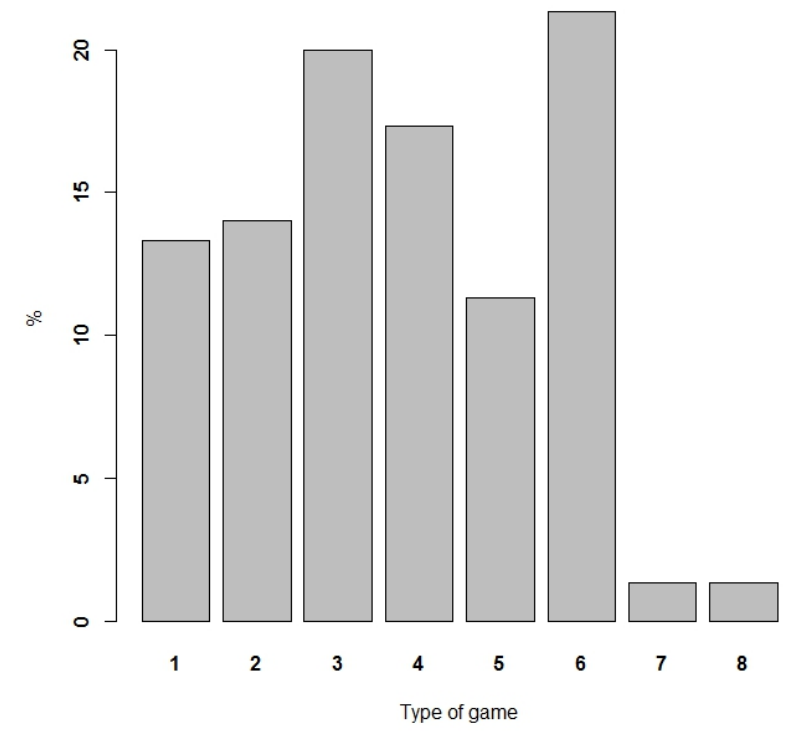

Fig. 3

Fig. 2. Professional context. The numbers in abscissa correspond to: 1) primary education; 2) secondary education; 3 ) higher education; 4) vocational studies; 5) university; 6) other education professionals (pedagogues, educational psychologists, etc.).

Fig. 3. Type of game. The numbers in abscissa correspond to: 1) symbolic; 2) construction; 3) strategy; 4) questions; 5) movement; 6) skill; 7) do not know / no answer; 8) other.

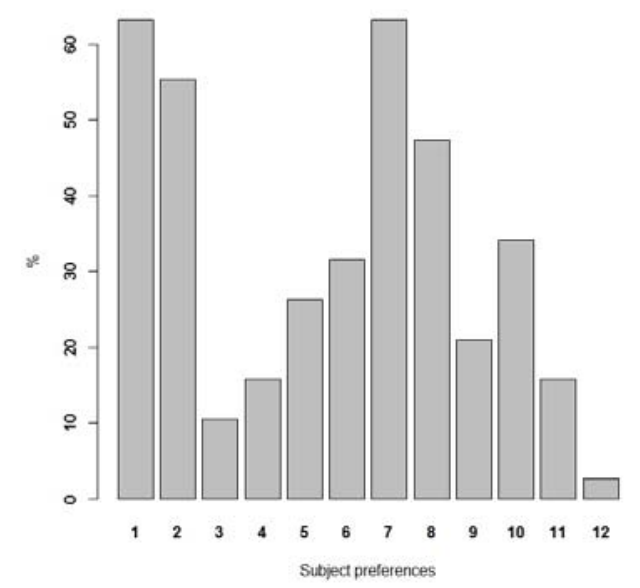

Fig. 4. Subject preferences. The numbers in abscissa correspond to: 1) nature and living organisms; 2) science and technology; 3) traffic rules; 4) sport and outdoor activities; 5) health and hygiene; 6) moral and ethical values; 7) multiculturalism, solidarity and tolerance; 8) calculation and reasoning; 9) music; 10) history; 11) language and understanding; 12) other.

\section{3. iPhone game}

\subsection{Description of the game}

The subject of the game is multiculturalism, tolerance, and solidarity. A crucial aspect that is related to multiculturalism, solidarity, and tolerance is knowledge. Our game focuses on transmitting knowledge about three of the world's poorest continents (Africa, Asia, and Central and South America). To cover the solidarity aspect, the mission of the game is to collect food from these continents to distribute it among poor people. To cover the multiculturalism aspect, while playing, the players learn about the food, animals, monuments, and meteorological phenomena that are typical of these continents. The objective is for children to realise that the typical food, the most common 
animals, or meteorological phenomena are different in other parts of the world. To cover the tolerance aspect, the game indirectly tries to promote respect for other people of different cultures (like the Africans) by helping them with different tasks. Using AR, the players explore a room searching for the objects requested by the guide character by focusing the iPhone camera on the different markers that are distributed throughout the room. Ten different AR markers were used and distributed in the activity room. When the requested object is food and it is found, the game transports the player to the typical place for collecting the food using a video game without AR. In this particular step of the game, the iPhone provides an augmented point of view (when the player is looking for the objects in the room) and also transports the player to the place where the food must be collected. The video games, which we will refer to as minigames, do not use AR, but they use tactile capabilities or the built-in accelerometer.

In order to familiarize the children with the game and its different ways of interaction they first follow a tutorial. The tutorial explains how to search for the objects that appear over the markers. The tutorial has the following structure:

1) Using AR, the players have to look for the guide character with a night-vision-glasses effect (this effect is simulated on the iPhone screen). The guide character appears only in one the markers distributed in the room. Once the guide character is found, a video shows up in which the guide character explains to the players who it is (Fig. 5).

2) When the guide character is found, she asks the players to perform several tasks. One of those tasks consists of opening an envelope with a mission inside it. To see the message, the players have to move each one of the fragments that make up the envelope. To do this, they have to touch the envelope fragments with a finger and drag them away until a piece of paper is revealed on the center of the screen. In order to read the paper, the players have to touch it. When touched, a message appears indicating the mission to be fulfilled. To destroy the message and pass to the next game screen, the players have to touch it again and it burns up (Fig. 6).

3) Finally, when all tasks are completed, the guide character gives definitions of multiculturalism, solidarity, and tolerance and states that the game tries to promote these values. After that, the guide character presents the main mission that has been entrusted to the players, which is "to collect food from three continents to distribute it among poor people". The tutorial ends here and the player is transported to the first continent.

It is worth pointing out that, in each screen, the guide character explains to the players how to perform the tasks. While playing, the game itself reminds the players of the task they have to perform every ten seconds. The order in which the continents are visited is, first Africa, second Asia, and finally Central and South America. Since the iPhone was used by children, it was protected to avoid damages (e.g. Fig. 5).

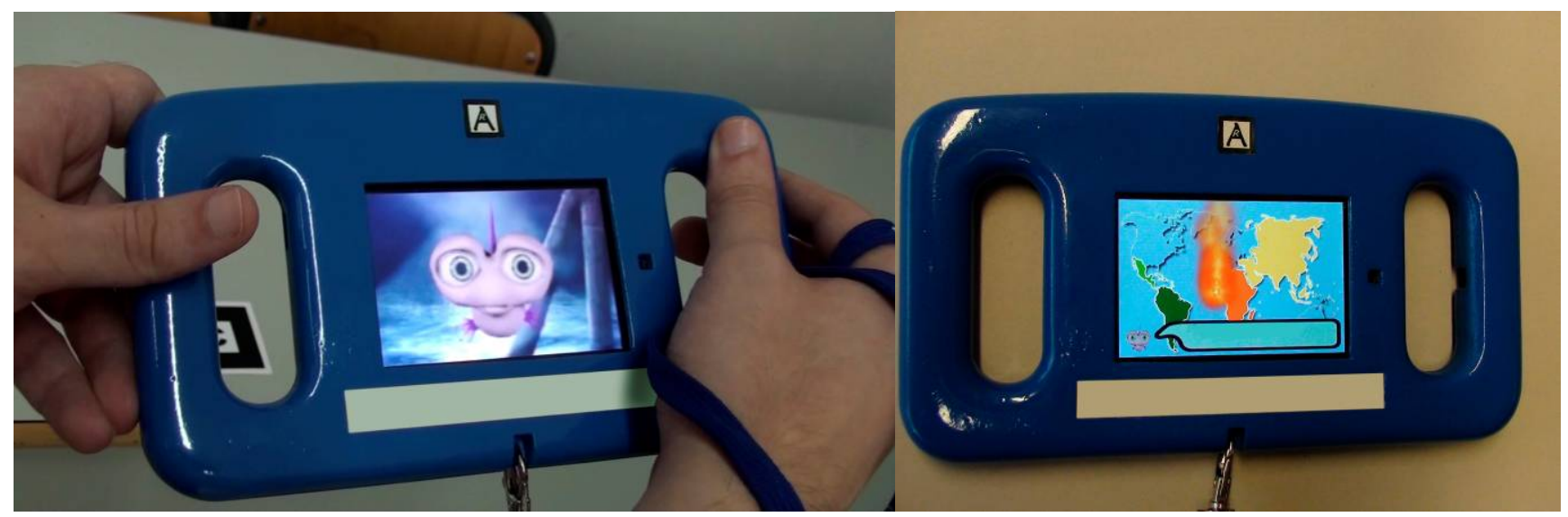

Fig. 5. The guide character is explaining the game

Fig. 6. The envelope is burned 


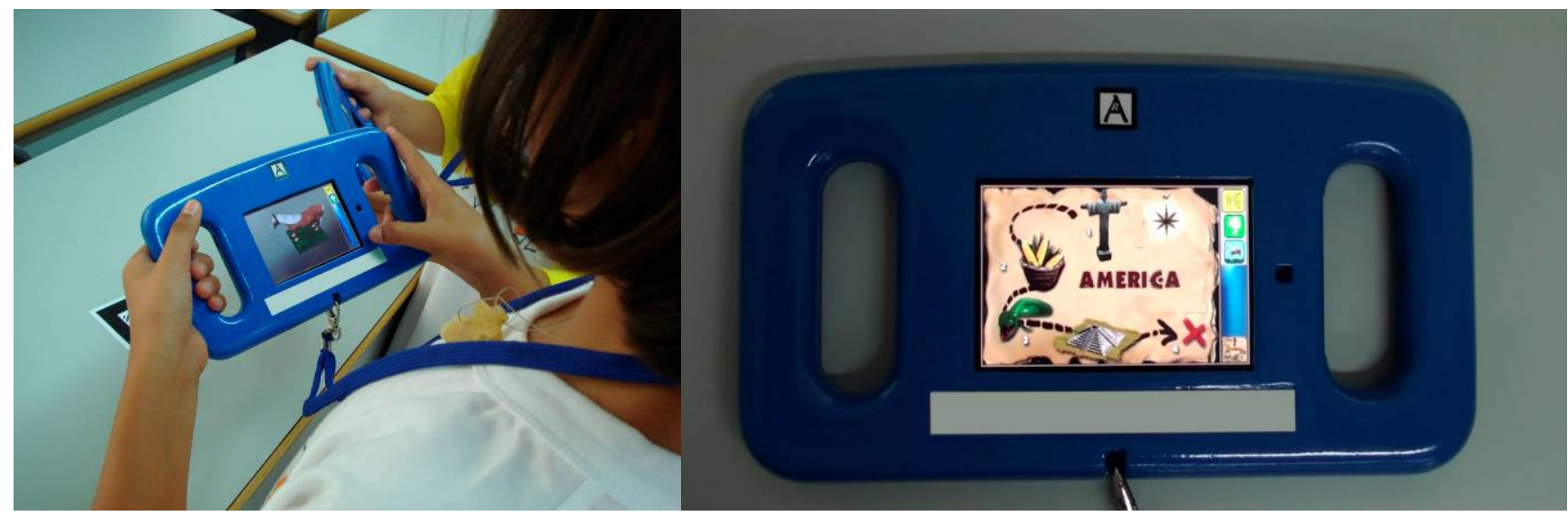

Fig. 7. A girl has found a horse

Fig. 8. Map for the mission in Central and South America

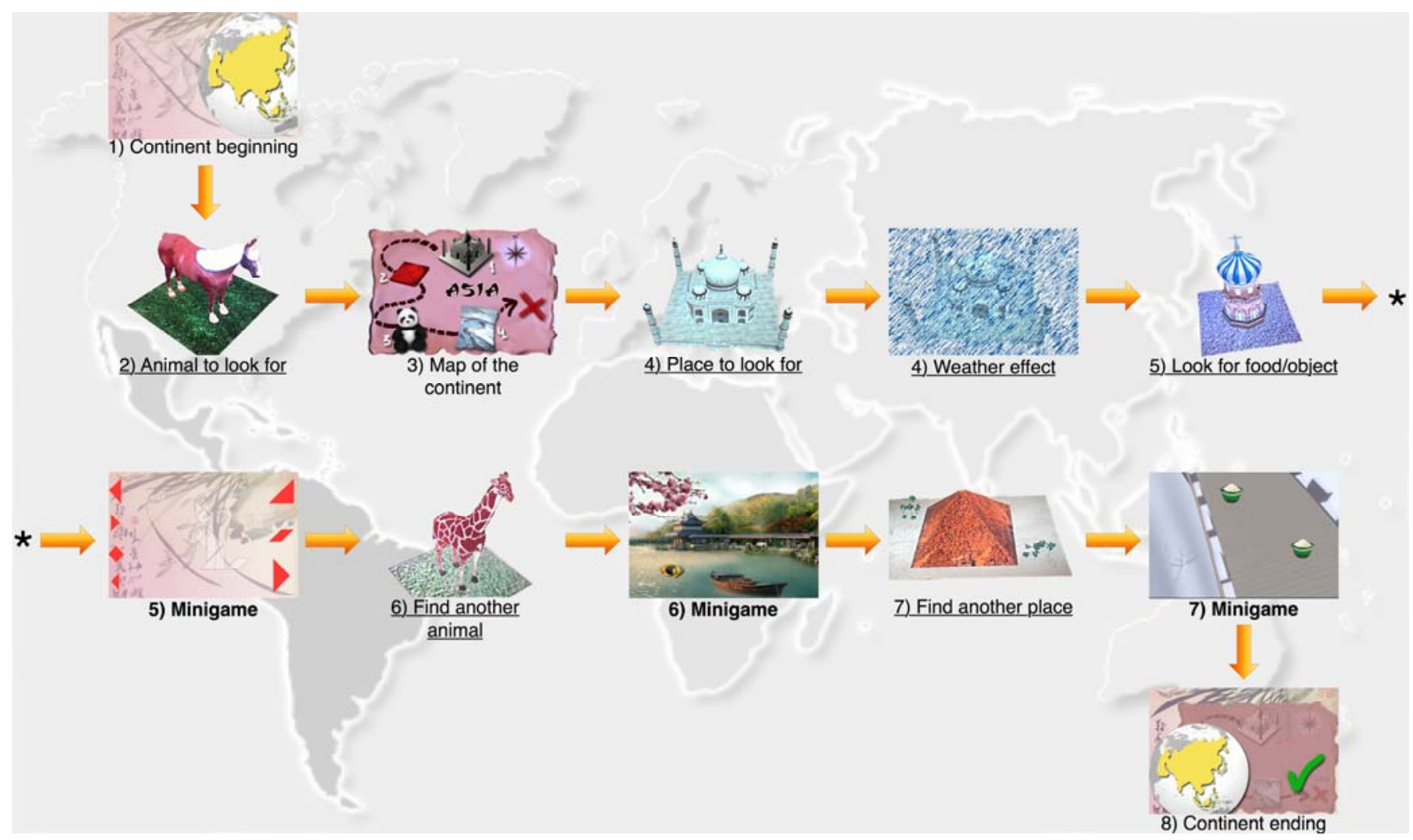

Fig. 9. Game steps. Underlined names indicate that the minigame uses AR. Bold names indicate that the minigames do not use AR. Normal names explain sections of the game.

The game follows the same steps for the three continents. Figure 9 shows these steps graphically.

1) The guide character presents some information about the continent to be visited (e.g. there are several spoken languages). The players learn about some of the important aspects of the continent, such as typical animals, food, and monuments/places.

2) The guide character shows the players the animal that they have to look for and reminds them how to do it (e.g. a horse, Fig. 7). Several animals are animated and move like a real animal. Several of them also make sounds that are similar to the characteristic sounds of a real animal. When the animal is found, the guide character gives information about it. This is done every time an animal, a monument or food is found. For example, when the players find the Kukulkan temple, the guide character tells them that it was built by the Mayans.

3) Once the animal is found, a map is shown to the players (Fig. 8). This map is available until they finish all the tasks of the continent. A button with the map image can be pressed to open or 
close the map view. This button is placed in the lower-right corner of the screen. The map shows the players what they have to look for.

4) Next, the guide character tells the players what place to look for (e.g. Christ the Redeemer). When that place is found, a weather effect is shown. The players have to eliminate this effect in order to advance in the game. To do it, they have to pass their finger from left to right on the iPhone screen.

5) The players have to look for a food/object (e.g. corncob). When that element is found, a minigame appears (Fig. 10).

6) The players have to find another animal (e.g. a snake). When the right animal is found, another minigame appears.

7) The players have to find another place (e.g. the Kukulkan temple). When that object is found, a new minigame appears (e.g. a labyrinth, Fig. 11).

8) Once the last minigame is completed, the guide character congratulates the players for helping it with the mission, and the game passes to another continent. If all three continents have been visited, then the game ends.

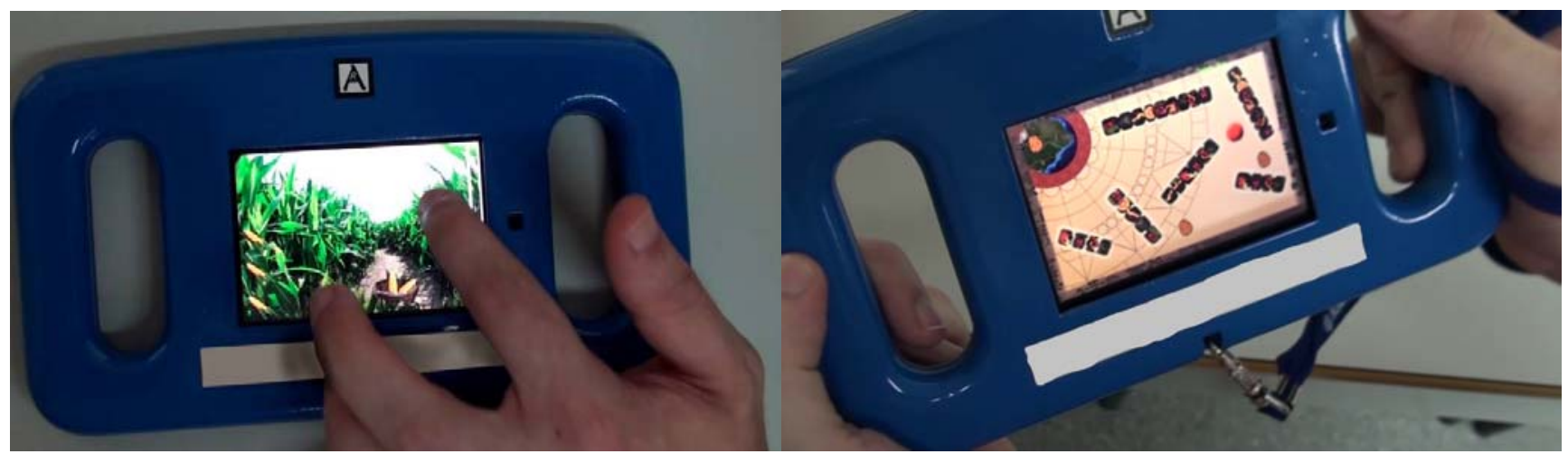

Fig. 10. Minigame for harvesting corncobs

Fig. 11. Labyrinth minigame

In our study, two children play the game at the same time using two different devices. They have to find the same element. When one of them finds it, he or she has to tell his/her partner. Therefore, they compete to be the first one to find the required object. They also collaborate with each other because they have to listen to the information together.

\subsection{Theoretical underpinnings}

In order to provide a comprehensive learning experience to the children, we have based the design of the game on two learning theories: the experiential learning theory by Kolb (1984) and the theory of multiple intelligences by Gardner (1983).

Experiential learning provides a theoretical underpinning to m-learning. According to Kolb (1984, p. 38), "learning is the process whereby knowledge is created through the transformation of experience", and experiential learning consists of the following steps: a concrete experience (do); a reflective observation (observe); an abstract conceptualization (think); and an active experience (planning or testing in new situations).

Our game also follows the constructivist theory by applying Gardner's theory of multiple intelligences (1983). In Gardner's theory, at least seven types of intelligence are considered: logicalmathematical, visual-spatial, linguistic, bodily-kinesthetic, musical-rhythmic, interpersonal, and intrapersonal. Since most students have several intellectual strengths and can use more than one of them (Reese \& College, 1998), we have tried to incorporate as many types of intelligence as possible besides the two that are usually considered, logical-mathematical and linguistic. This way, our game should reach the vast majority of the students and ensure that nobody is left behind. 
With regard to the use of the two theories in our study, Kolb's theory might provide complementary pedagogical support to Gardner's concepts of multiple intelligences (Hanratty \& Taggart, 2005). The experiential learning theory of Kolb suggests the importance of applying knowledge and working in real settings; Gardner's theory reinforces the importance of these forms of learning but also suggests considering more than one learning approach (Kezar, 2001). Like Kolb's experiential learning theory, Gardner's theory of Multiple Intelligences suggests that individuals have different preferences and aptitudes for different types of learning (Godwin \& Kaplan, 2008; Healy \& Jenkins, 2000) and that experiential education facilitates those different learning styles and enables pupils to participate more through the various stages of learning (Hanratty \& Taggart, 2005). Our game design was based on the underlying idea of using experience for learning. With our game, children not only observe (as in a classroom lesson) but also participate by playing the game, experiencing the different situations that the game offers with a combination of different learning styles. For example, the multiple forms of intelligence that the game uses are: for bodily-kinesthetic intelligence, the children have to explore a room to find the element requested by the guide character. For visual-spatial intelligence, the game is mostly visual and also allows players to look at objects from different points of view (not only from the front, but also from the back). For musical intelligence, the game transfers the information through musical patterns (e.g. the typical sounds of different animals). For interpersonal intelligence, the game is played in pairs. Since the game is played in pairs and players have to find the same element, they must compete to be the first one to find the element. This competition helps to identify their strengths and weaknesses. We can find a more concrete example of this by analyzing one minigame. For example, when players have to collect food, they have a concrete learning experience about that particular food. They experience reflective observation through the feedback of the game. Feedback is an important issue for the design of systems of this type (e.g. for integrated learning systems, Wood et al., 1999) and also for good performance (e.g. Burgos et al., 2007). We introduce only the feedback that is required to get the best performance. These previous phases allow abstraction and generalization, adding meaning to the experience. The acquired concepts can be used actively in new situations (e.g. daily life) (Kolb's theory). However, at the same time, this minigame about collecting food also uses several forms of intelligence to stimulate the player. For example, the children have to hear and read the instructions that the guide character gives them in order to collect the food (linguistic intelligence); the children have to solve the problem of collecting food (logical-mathematical); the music and sound effects in the minigame allow the children to get into the gameplay and reinforce their feelings of accomplishment and self-esteem (musical intelligence); the game relies heavily on visual content and, when collecting food, the children have to look for the food and put it in a basket (visual-spatial intelligence).

\subsection{Design issues}

To develop our game, we followed the systems development life cycle (SDLC). The SDLC model is a modern structured approach for describing the complex processes and issues involved in information systems development. It is a general framework that can be found in many different systems development methodologies (Zhang, Carey, Te'eni \& Tremaine, 2005). In our case, we can identify six phases: Project Planning and Selection, System Analysis, System Design, System Implementation, Testing, and Evaluation. It is important to note that some phases like System Design, System Implementation, and Testing are not completely independent and can be blended with each other.

To select the subject and the type of game to develop, and to know the opinion of the professionals in education, we performed a preliminary study in the Project Planning and Selection phase. The results of the preliminary study indicated that the most appropriate subjects were: multiculturalism, solidarity, and tolerance; and nature and living organisms. We chose multiculturalism, solidarity and tolerance for three reasons. First, it was one of the preferences of the preliminary study. Second, it was also the theme chosen by the school where the game was going to be tested. Third, these subjects are 
covered in the Spanish law for primary education. Article three of the royal decree 1513/2006 of December $7^{\text {th }}$ establishes the following as an objective of primary education: "To know, understand and respect different cultures and differences between people, equal rights and opportunities for men and women, and non-discrimination against people with disabilities". In its fifth competence, social and civic competence, the decree establishes that students should reflect critically upon various concepts, including solidarity.

We also based the design of our game on the results obtained in our preliminary study for preferences of type of game. The preferred one was the game of skill. This is why the interaction of a great part of our game requires some skills. The preference within this category was for simulation. The explanation included in the questionnaire was the following: "Simulation games simulate activities and experiences that cannot be easily accessible in real life. They use complex strategies and they require confronting new situations (driving race cars, planes, etc.)". We tried to develop the video games that are included in our game to satisfy this preference. For example, this is why the children have to guide some food that randomly appears or comes down from the top of the screen to the right location (e.g. to a basket).

In the System Analysis phase, we determined the device to use and the system requirements, and we identified the target users. As explained in Section 1.4, we decided to use the iPhone because it provides the necessary capabilities for developing an AR game (e.g., an integrated camera).

Furthermore, the iPhone provides multi-touch and accelerometer interactions. We also thought that using the iPhone was a good idea because it is one of the most widely used smartphones. In this phase, we also determined the power capabilities of the device in order to have a smooth experience with the game. We found that a 3D model with approximately 6000 polygons was the limit for drawing on screen because the game became too slow when the iPhone camera and the AR tracking capabilities were turned on. Finally, we identified our target audience, which was based on the type of game we wanted to implement, the subject of the game, and the device used.

In the System Design phase, the design team described every stage of the game that would later be implemented. During this phase, questionnaires were proposed as a method to evaluate the game with children. In this phase, the forms of interaction were also established in order to develop a more playful game (physical manipulation, touch-screen interaction, etc.). We also tried to make this interaction as good as possible. Good interaction is one of the most important factors that influence a gaming experience (Koh et al., 2010). To develop our game, we took into account previous studies that have provided several design principles and suggestions for m-learning (Herrington et al., 2009) and also for AR applications (Koh et al., 2010). Although the design principles suggested by Herrington et al. (2009) were intended for higher education, we consider several of them to be suitable for primary education. The design principles for m-learning suggested by Herrington et al. (2009) that can be applied to our work are the following:

1) Real world relevance: Use m-learning in authentic contexts. Since our game is an AR game, it is played in the real world.

2) Mobile contexts: Use m-learning in contexts where learners are mobile. We use an iPhone, which allows the learner to be mobile across space and time, with different topics (future work).

3) Explore: Provide time for exploration of mobile technologies. Our game starts with a short tutorial. This tutorial explains the different ways of interaction that are used in the game. We have also included a 'friendly pet' in the introduction to guide the children during their learning activity.

4) Whenever: Use m-learning spontaneously. Our game can be played at any time.

5) Wherever: Use m-learning in non-traditional learning spaces. Our game can be played in any space, not only in the classroom. 
6) Whomsoever: Use m-learning both individually and collaboratively. In our game, the learning is individual, but it requires the collaboration of two children playing at the same time in order to be able to proceed to the next step.

7) Affordances: Exploit the affordances of mobile technologies. We use the innovative features of the iPhone. We use the iPhone camera to capture the real world. We use the iPhone tactile screen and its accelerometer for interaction.

The design principles for AR applications can be summarized as follows (Koh et al., 2010):

1) A mobile phone with a built-in camera is an interaction device with 6 degrees of freedom (Henrysson \& Billinghurst, 2007). This device can be used as a tracking device. We use the iPhone camera to track the marker.

2) For mobile AR user interfaces, the use of the additional degree of freedom that is available on the mobile phone with respect to desktop metaphors is suggested (Diverdi et al., 2003). Our game incorporates this.

3) AR can use several input channels. A combination of these different input channels is suggested (Sandor \& Klinker, 2005). Our AR game uses the camera to track the marker and the tactile screen to select the virtual objects.

4) For fiducial marker tracking in mobile AR applications, it is suggested to consider tangible AR techniques (Kato et al., 2001). The interaction can be more natural and intuitive. In our game, the interaction is both tangible and tactile. It is tangible because the children can manipulate the markers, and it is tactile because they use the tactile screen for selection.

5) Creation of appropriate interaction techniques for AR applications that are as intuitive as possible (Zhou et al., 2008). We have tried to use the most intuitive interaction techniques possible. The interaction is both tangible and tactile.

In our game, we have also incorporated a shift from an external perspective to an embedded agent. This shift consists of a combination of AR for an external perspective and video games for an embedded agent. For example, when the requested object is food (e.g. corncob) and a player finds it, the game transports the player to the typical place for collecting the food (a cornfield) using a video game without AR. This shift allows the player to become part of the game and creates a more engaging player experience (Dickey, 2005). We have implemented a Continuous Natural User Interface using this shift. Finally, only the information required in each step is presented in order to avoid distracting the players (Vitzthum, 2006).

In the System Implementation phase, one part of the team wrote the code to develop the game. During this phase, the entire team also played the game in order to test the application. The team members that wrote the code presented vertical prototypes to the other team members to observe how the different stages and interaction forms worked. This way, we could apply some changes if the game stage did not work as it was intended.

In the Testing phase, we tested the game with children. Several problems that were not initially detected within the team testing were debugged and corrected.

In the Evaluation phase, a study was carried out where the iPhone game was compared to traditional games that offered an equivalent experience and transmitted the same information to the children. The survey questionnaires described above were used to evaluate the different features of the game, such as the ease of use, the acquired knowledge, the engagement and fun, etc.

\subsection{Technical features}

The technical requirements for developing and running the iPhone game were the following:

1) The Xcode 3 IDE and the iPhone SDK 3. The version used in this work was Xcode 3.2.2 with the iPhone SDK 3.2.

2) An iPhone $3 \mathrm{GS}$ with the iOS 3 operating system. The version of the iPhone operating system used in this work was 3.1.3. 
We developed our game using event-driven programming and Objective-C as a programming language. To include AR capabilities, we used ARToolKitPlus 2.1.1. We used a game engine, SIO2 1.4 version, to develop the game (sio2interactive.com). SIO2 is written in C. It uses the OpenGL-ES 1.1 version and can import scenes created from Blender as well as other features. In our game, the 3D objects were modeled with Blender.

\section{Study}

\subsection{Participants}

Eighty-four children from ages 8 to 10 years old took part in the study ( 8 years old (28\%), 9 years old ( $50 \%), 10$ years old (22\%); 38 boys (45\%), 46 girls $(55 \%)$ ). The children attended the summer school of the Technical University of Valencia (Escola d'Estiu). The parents signed a consent form to allow their children to participate in this study.

\subsection{Traditional game}

To compare the AR game, we designed several traditional games so that the children received the same information as in the iPhone game. Moreover, an adult guided the children during the game and explained everything to them. If they did not understand something, the adult repeated the message and made sure that the information always arrived to the students. Figure 12 shows the elements used in these traditional games.

Every minigame played on the iPhone had its equivalent in a traditional form. The same information was transmitted to the children, independent of the method they used (traditional or iPhone). After finding the requested element (animal, monument, or food) or prior to the search request, the person in charge of the activity (traditional) or the iPhone game gave exactly the same information to the children. Table 2 shows a comparison of the Central and South America continent between the iPhone and the traditional methods.

Table 2. Comparison chart of the information transmitted about Central and South America for the traditional and iPhone games.

\begin{tabular}{|l|l|l|}
\hline Game & Traditional & iPhone \\
\hline Introduction & $\begin{array}{l}\text { The person in charge shows a printed world map with } \\
\text { elements to find. This person focuses on Central and South } \\
\text { America and gives some details about the continent, cites } \\
\text { the two main foods, indicates the animal that they have to } \\
\text { find first, and gives information about this animal. }\end{array}$ & $\begin{array}{l}\text { A map with the elements to find } \\
\text { appears on the iPhone screen. The } \\
\text { guide character gives the same } \\
\text { information as in the traditional game. }\end{array}$ \\
\hline Find a horse & $\begin{array}{l}\text { The children have to find the horse on a printed board on } \\
\text { which there are many more animals than the animal they } \\
\text { have to look for (Fig. 11). }\end{array}$ & $\begin{array}{l}\text { The children have to find the horse } \\
\text { making use of the AR capabilities of } \\
\text { the device. The guide character gives } \\
\text { the same information as in the } \\
\text { traditional game. }\end{array}$ \\
\hline Find Christ the & $\begin{array}{l}\text { The children use the horse to travel around the continent. } \\
\text { Rederson in charge asks the children to find Christ the } \\
\text { Reen this image on the world map. After finding Christ the } \\
\text { Redeemer, the person in charge gives information about its } \\
\text { location and relevant details. }\end{array}$ & $\begin{array}{l}\text { The children have to find the } \\
\text { monument making use of the AR } \\
\text { capabilities of the device. The children } \\
\text { have previously seen this image on the } \\
\text { map. The guide character gives the } \\
\text { same information as in the traditional } \\
\text { game. }\end{array}$ \\
\hline Harvest corn & $\begin{array}{l}\text { The children throw balls covered with velcro to stick on a } \\
\text { corncob (made with special material) placed on a wall. The } \\
\text { information that is presented to the children is similar to } \\
\text { previous cases. }\end{array}$ & $\begin{array}{l}\text { To harvest corn, they have to drag it to } \\
\text { a basket using the tactile capabilities of } \\
\text { the iPhone. }\end{array}$ \\
\hline
\end{tabular}




\begin{tabular}{|l|l|l|}
\hline Find a snake & $\begin{array}{l}\text { The children have to find the snake on a printed board in } \\
\text { which there are many more animals than the animal they } \\
\text { have to look for. The information that is presented to the } \\
\text { children is similar to previous cases. }\end{array}$ & $\begin{array}{l}\text { The children have to find the snake } \\
\text { making use of the AR capabilities of } \\
\text { the device and have to wind the snake } \\
\text { onto a branch. }\end{array}$ \\
\hline $\begin{array}{l}\text { Find the Temple } \\
\text { of Kukulkan and } \\
\text { harvest the } \\
\text { potatoes }\end{array}$ & $\begin{array}{l}\text { To harvest potatoes, a printed labyrinth is used in which the } \\
\text { children have to arrive to its center (Fig. 12). The } \\
\text { information that is presented to the children is similar to } \\
\text { previous cases. }\end{array}$ & $\begin{array}{l}\text { To harvest potatoes, the children have } \\
\text { to tilt the device in order to move a ball } \\
\text { to collect the food. }\end{array}$ \\
\hline
\end{tabular}

Other examples of traditional games were: To harvest rice, they had to look for five black grains of rice that were mixed in a bowl with normal rice. To harvest dates, they had to pick the balls that were attached to a palm tree. To harvest potatoes, a printed labyrinth was used in which the children had to arrive to its center (Fig. 13). To complete a tangram, a real tangram was used and children had to place the pieces in order to copy the original figure.

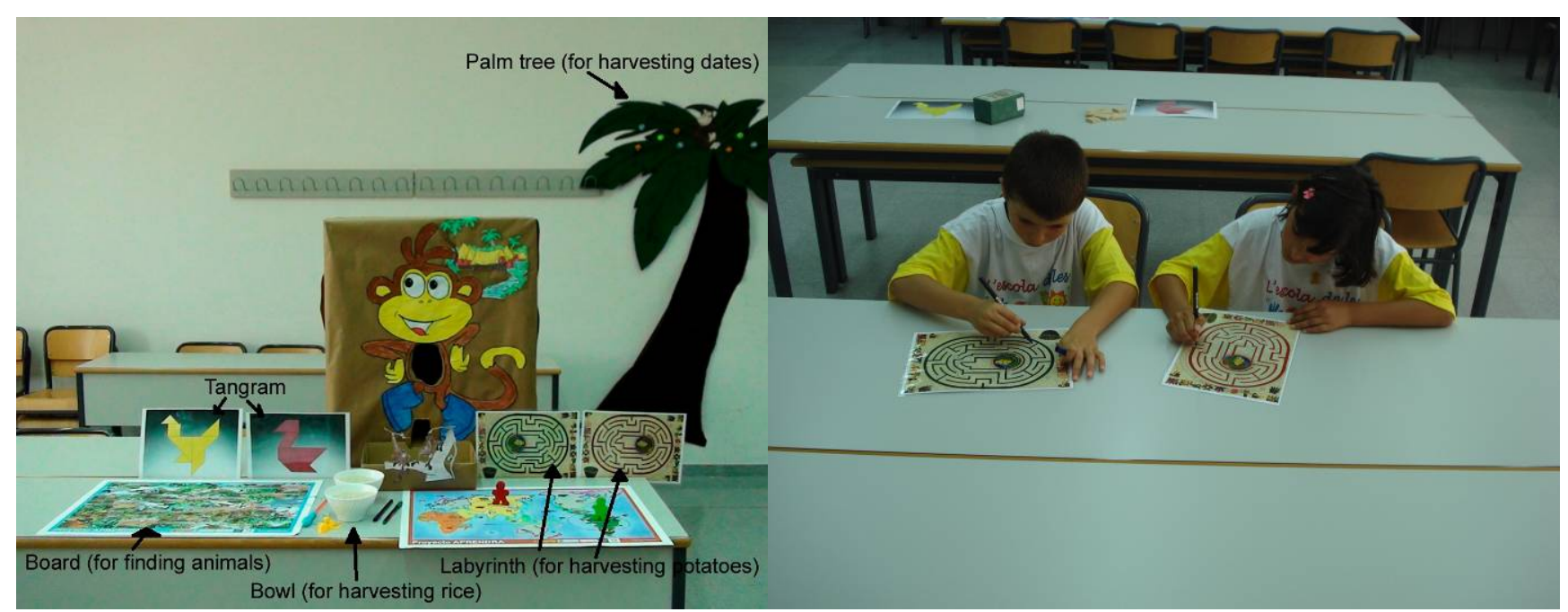

Fig. 12. Elements used in the traditional game

Fig. 13. Two children playing with the real labyrinth game

\subsection{Measurements}

Two questionnaires were used for the validation. The first one (QRA1 or QTR1) was composed of 19 questions. The first 14 questions were designed to evaluate the children's degree of knowledge after playing with either the iPhone game or a traditional one. They were multiple-choice questions with 3 or 4 possible answers scoring as success or fail. As an example, one of these questions was: Dromedaries are animals that normally live in a) African deserts, b) Asian forests, $c$ ) the great fields of corn of America. Ten of the 14 questions were related to multiculturalism. The remaining 4 were related to solidarity. But, the main goal of the game was also related to solidarity. The tolerance aspect was not directly considered in the knowledge questions. However, the game indirectly promotes tolerance by including tasks that require knowledge about other cultures (e.g. helping people with different races such as Caucasians, Africans or Asians).

The last 5 questions of the first questionnaire were related to the participant's satisfaction with the game that they played. The first four of these last 5 questions were multiple-choice questions with 3 to 5 possible answers. These first four questions were related to: 1) the experienced amusement; 2) perceived learning; 3 ) if they would like to visit the places visited in the game; 4) if they would like to play again to know other places. These four questions were used as the satisfaction variable. The last question was: Score the game from 1 to 10 , where 1 was the lowest value and 10 was the highest value.

The second questionnaire (QRA2 or QTR2) was focused on knowing the children's preferences and their opinion about the iPhone game and the AR experience. It had 12 questions. The first 11 were 
multiple-choice questions with 3 to 5 possible answers. As an example, the first question of this second questionnaire was: How often do you play with consoles (e.g. Wii) or computer games?, a) every day; b) nearly every day; c) some days; d) hardly ever; e) never. Another of these questions was: Has it been easy to play with the iPhone game? 1) strongly disagree; 2) disagree; 3) neither agree nor disagree; 4) agree; 5) strongly agree. Questions 6 and 8 had three subscales with 4 possible options each. For example, question 6 was: Mark what you liked the most about each continent. The three subscales corresponded to Africa, Asia, and America, and there were four possibilities for each subscale. There were four possibilities for each continent. For example, for Africa, a) the sand storm; b) the peanuts minigame; $c$ ) the dromedary and the giraffe; d) the dates minigame. Question 12, the last question, was used to determine which game the children preferred, the iPhone game or the traditional game.

\subsection{Procedure}

The children voluntarily participated in this study with the consent of their parents. They were counterbalanced and randomly assigned to one of two conditions:

a) Children who played the iPhone game first and then the traditional game.

b) Children who played the traditional game first and then the iPhone game.

After playing the iPhone game, the children in the first group (a) filled out the QRA1. Then they played the traditional game and filled out the QTR2. After playing the traditional game, the children in the second group (b) filled out the QTR1. Then they played the iPhone game and filled out the QRA2. The questionnaires were filled out in the same room where the activities took place and were monitored by the person in charge of the activity. This person interfered as little as possible during the activity. He gave the iPhone to the children and they started playing. It is important to note that, with the iPhone, it was not possible to hear a message again once it had already been heard. The person in charge also took notes of the players using an observation sheet. The observation sheet for the traditional game was composed of 7 sections related to initial behavior, initial motivation, understanding of how to play the game, engagement and fun, behavior during the game, cooperation between the users, and perceived understanding of the concepts explained in the game. There was also an additional section were they could add other perceptions that did not pertain to the sections described. Every section had a scoring scale from 1 to 10 in which the person observing the players could score the performance of the players in each one of the aspects mentioned. There was also a free space in each section in which the observer could take notes about the players. The observation sheet for the iPhone game contained the same sections as the traditional observation sheet plus one more section that was related to the interaction with the device.

\subsection{Variables}

Several dependent variables were used in the analysis. A knowledge variable was used to evaluate the knowledge acquired by playing the games. This variable was created by counting the number of correct answers from 14 questions of the QRA1 and QTR1 questionnaires. We also measured the perceived learning variable with a question to see the differences with real learning. As Section 4.3 explains, a satisfaction variable was defined using questions related to the degree of satisfaction experienced during the game. This variable was composed of four questions from QRA1 and QTR1. A preference variable was used to determine which game the children preferred, the iPhone game or the traditional game. The following independent variables were considered in the analysis: gender, 1) boy, 2) girl; the group , 1) the group that experienced the iPhone game first, 2) the group that experienced the traditional game first; and the academic grade, 1) 3rd, 2) 4th. The age was also included (it ranged from 8 to 10 years old), but it was finally discarded because it was considered to be redundant with the grade, and the interaction between both factors is known a priori. 


\section{Results}

\subsection{The net generation}

The objective of the study is to determine whether the participants can be considered to be 'net generation' members. In our case, for the frequency of playing with consoles or computer games, the children answered question 1 from QAR2 and QTR2: How often do you play with consoles (such as the Wii) or computer games? 1) never; 2) hardly ever; 3) some days; 4) nearly every day; 5) daily. Figure 14 shows the results, where it can be observed that most children play some days or nearly every day and very few children never play, while $14 \%$ of the children play daily. We studied the relation of this question with the gender and grade factors. A multifactorial ANOVA revealed significant effects on gender $\left(F[1,82]=20.27, p<0.001\right.$, partial $\left.\eta^{2}=0.20\right)$, but there was no significant effect on grade $\left(F[1,82]=3.89, p=0.05\right.$, partial $\left.\eta^{2}=0.05\right)$, and there was no interaction between the two factors $\left(\mathrm{F}[1,84]=0.002, \mathrm{p}=0.97\right.$, partial $\left.\eta^{2}<0.001\right)$, as Figure 15 shows. These results corroborated the worldwide trend of previous studies carried out in other countries as discussed in Section 6.3.

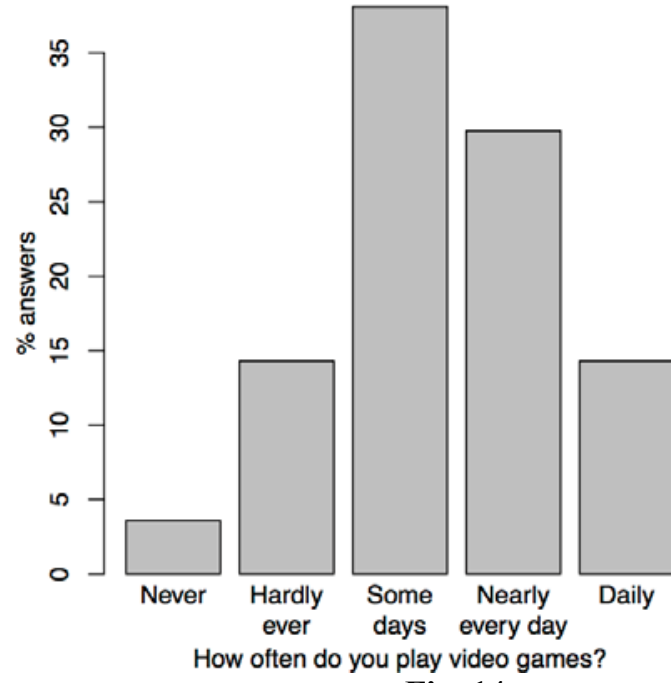

Fig. 14

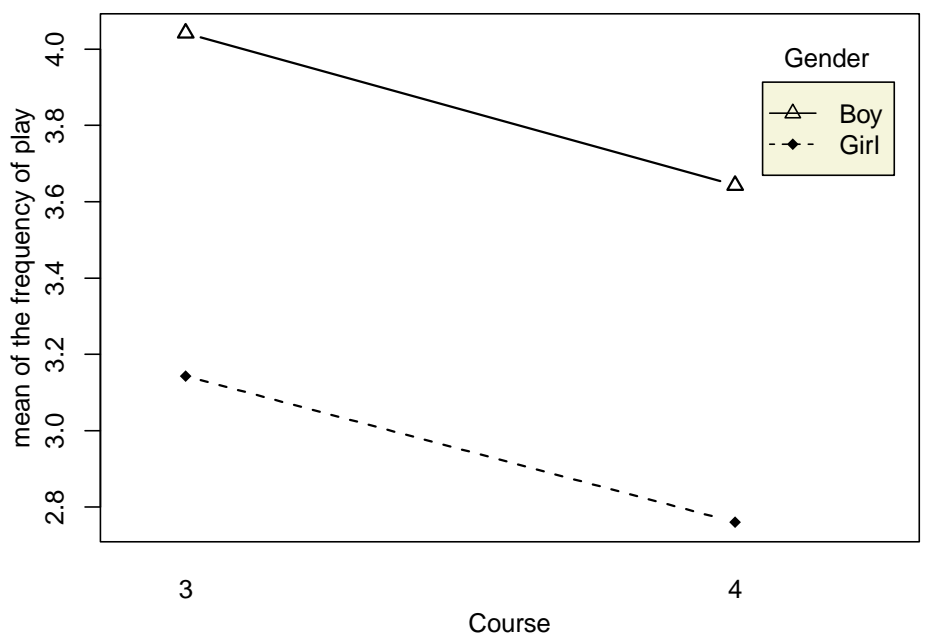

Fig. 15

Fig. 14. Total number of answers given to the question about the frequency of playing video games.

Fig. 15. Mean of the frequency of playing with consoles or computer games for the grade separated by gender. The frequencies are rated as: 1) never; 2) hardly ever; 3) some days; 4) nearly every day; 5) daily.

\subsection{Learning outcomes}

In order to determine if the experience with the iPhone game or the traditional game influenced the number of correct answers, a t-test was performed. The analysis showed that the difference in the knowledge variable (QAR1 and QTR1) between the iPhone game (mean 9.02 \pm 2.23 ) and traditional learning (mean 10 \pm 1.75$)$ was not significant at level $0.01(\mathrm{t}[82]=-2.21, \mathrm{p}=0.03$, Cohen's $d=0.48)$. The p-value and the medium effect size of Cohen's $d$ indicated no real differences between the two groups. Therefore, we concluded that there was not a significant difference in the scores between the iPhone group and the traditional group.

The t-test took into consideration the isolated effect of the factor of the group, but it is also interesting to see the effects of other factors when combined, such as gender and grade. A multifactorial ANOVA was performed to analyze the effect of several factors combined. This ANOVA studied the effect on the knowledge variable of the group, gender, and grade of the children. As Table 3 shows, there was not any factor that had significant effects on the correct answers. All p-values were above alpha $=0.01$, and the size of the effect $\left(\right.$ partial $\eta^{2}$ ) for all the factors was very small. Special mention should be made about the grade because it had a very high p-value and a very low effect size, possibly due to a strong balance in the answers. Furthermore, there was no interaction among the factors given the clearly high p-values and low effect sizes, as the last rows of Table 3 show. 
The children were also questioned about their perceived learning beliefs (perceived learning variable from QAR1 and QTR1). A total of $100 \%$ of the participants in the iPhone group thought they had learned using the iPhone game, while $93 \%$ of the participants in the traditional group thought they had learned using the traditional game. To determine if the independent variables influenced the answers, Fisher's exact tests were performed (the Chi squared test was not appropriate because some values were very small). This test revealed that there were no significant differences $(p=0.241)$. Therefore, we could deduce that being in the iPhone group or in the traditional group did not suppose a difference in the degree of perceived learning. Furthermore, the grade $(p=0.21)$ and the gender $(p=$ 0.72) did not influence perceived learning, either.

Table 3. Results of the multifactorial ANOVA. Three factors (Group, Gender, and Grade) and their combinations were analyzed for the number of correct answers in the tests $(n=84)$.

\begin{tabular}{llllll}
\hline Factor & Sum sq. & df. & F & p-value & Partial $\boldsymbol{\eta}^{\mathbf{2}}$ \\
\hline Group & 22.01 & 1 & 5.43 & 0.02 & 0.07 \\
\hline Gender & 11.98 & 1 & 2.95 & 0.09 & 0.04 \\
Grade & 0.002 & 1 & $<0.01$ & 0.98 & $<0.001$ \\
\hline Group:Gender & 1.76 & 1 & 0.43 & 0.51 & 0.01 \\
\hline Group:Grade & 6.35 & 1 & 1.56 & 0.21 & 0.02 \\
\hline Gender:Grade & 0.19 & 1 & 0.05 & 0.83 & $<0.001$ \\
Group:Gender:Grade & 10.56 & 1 & 2.60 & 0.11 & 0.03 \\
Residuals & 308.36 & 76 & & & \\
\hline
\end{tabular}

\subsection{Other aspects considered}

With regard to the introduction of AR in school (question 11 in QAR2 and QTR2), the majority (91\%) indicated they would like to use AR in the classroom; only $2 \%$ of participants were not interested in this possibility, and the rest were undecided. For the preference of game (iPhone or traditional, question 12 in QAR2 and QTR2), the answers of the participants to the question asking them to choose their favorite game were analyzed with the independent variables. The data gathered was categorical and the Chi squared test was used. The results indicated that the group $\left(X^{2}[1]=3.78, p\right.$ $=0.05)$, the gender $\left(\mathrm{X}^{2}[1]=0.17, \mathrm{p}=0.68\right)$, and the grade $\left(\mathrm{X}^{2}[1]=0.36, \mathrm{p}=0.55\right)$ had no influence on the preference variable. Figure 16 shows that the variances in the variables are very low. However, in all cases, the vast majority preferred the iPhone game ( $90 \%$ of the children) over the traditional game. Moreover, 96\% percent of the children indicated they would like to play with the iPhone game again (question 18 in QAR1 and QTR1).
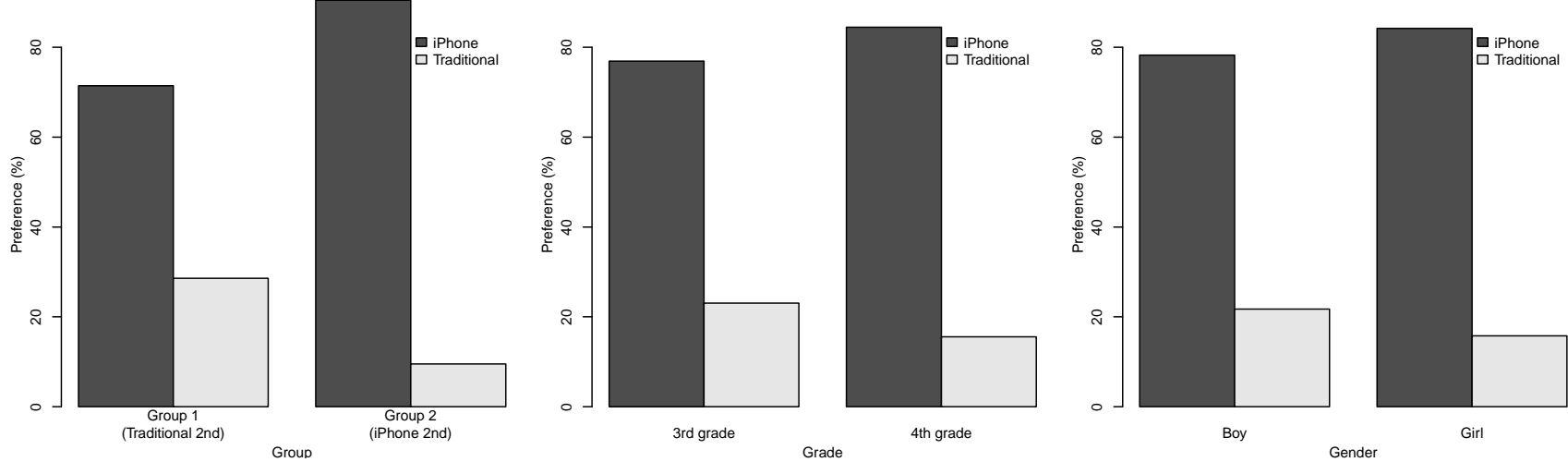

Fig. 16. Graphics for the dependent variable preference for the independent variables Group, Grade, and Gender $(n=84)$

To determine whether there was a significant difference in the level of satisfaction experienced by the two groups (satisfaction variable from QAR1 and QTR1), a t-test was performed. The responses to this question indicated that the difference in the level of amusement between the iPhone group (mean 
$3.37 \pm 0.27$ ) and the traditional group (mean 3.33 \pm 0.30 ) was not significant $(\mathrm{t}[82]=0.57, \mathrm{p}=0.57$, Cohen's $d=0.09$ ). From this analysis, it was possible to deduce that the difference in the data was due to chance.

The satisfaction of the participants was also analyzed in a multifactorial ANOVA with the combination of the factors group, gender and grade. The result is shown in Table 4, where it can be observed that there were no significant effects, as all p-values are very high and the effect sizes of the partial $\eta^{2}$ are very low. No interactions were found among the independent factors analyzed, as the last rows of Table 4 show.

Table 4. Results of the multifactorial ANOVA. Three factors (Group, Gender, and Grade) and their combinations were analyzed for the satisfaction variable $(n=84)$.

\begin{tabular}{|c|c|c|c|c|c|}
\hline Factor & Sum sq. & df. & $\mathbf{F}$ & p-value & Partial $\eta^{2}$ \\
\hline Group & 0.01 & 1 & 0.13 & 0.72 & 0.01 \\
\hline Gender & 0.01 & 1 & 0.12 & 0.72 & 0.001 \\
\hline Grade & 0.08 & 1 & 0.91 & 0.35 & $<0.001$ \\
\hline Group:Gender & 0.02 & 1 & 00.21 & 0.65 & $<0.001$ \\
\hline Group:Grade & 0.10 & 1 & 1.20 & 0.28 & 0.001 \\
\hline Gender:Grade & 0.02 & 1 & 0.19 & 0.67 & $<0.001$ \\
\hline Group:Gender:Grade & 0.03 & 1 & 0.35 & 0.56 & 0.04 \\
\hline Residuals & 6.68 & 76 & & & \\
\hline
\end{tabular}

For the ease of play (question 4 in QAR2 and QTR2), 49\% of the participants considered the iPhone extremely easy to play, manipulate, and interact with; $37 \%$ of the participants considered it very easy to play with; and $11 \%$ of the participants considered it slightly easy to play with. Only $3 \%$ thought that it was not at all easy to play with.

For the preferred continent (question 6 in QAR2 and QTR2), most players preferred the Central \& South American activities (45\%), followed by the African (28\%) and Asian activities (27\%). Finally, for the preferred game, in the Central \& South American continent, the majority $(65 \%)$ chose the labyrinth (the only minigame that used the accelerometer).

Finally, we studied the correlations among the three main variables (knowledge, satisfaction, and preference). We found that all of them were below 0.2 , indicating that these variables are independent from each other.

\subsection{Observation sheets}

An analysis of the scores and comments given by the people that were observing the players shows that similar results to those found in the questionnaires QRA1 and QTR1 were obtained. Figures 17 and 18 show the scores given to every section by the observers in the traditional and iPhone methods, respectively. ANOVA analyses were performed for each aspect observed to determine if the observer's perceptions differed depending on whether the iPhone game or the traditional game was used. No differences were found in any of the aspects analyzed with regard to the order of play. No differences were found with regard to the method used (Traditional or iPhone) with the exception of the perceived understanding of the concepts explained in the game $\left(F[1,38]=14.53, p<0.01\right.$, partial $\left.\eta^{2}=0.28\right)$. The people in charge of the activities thought that the players understood the concepts better when using the traditional method $(8.60 \pm 0.85)$ than when using the iPhone game $(7.56 \pm 0.86)$. However, the scores were quite high in both cases, and the observers commented that the players were paying attention to the explanations given by the iPhone game or the person guiding the traditional game. With regard to the initial behavior and motivation of the players, the observers said that it was very good (they gave an average score of $8.06 \pm 1.11$ to the iPhone players and $7.82 \pm 1.10$ to the traditional players). With regard to the understanding of how to play the game, the people observing the players thought that a great majority of them did not have any trouble playing the game after the tutorial section when using 
the iPhone. The observers also said that the players handled the device without problems. The same happened with the traditional game, where the players did not have any major problem playing the minigames. These results would support the ones obtained for the ease to play, where only a $3 \%$ of players thought it was not easy to play the game. The behavior of the players during the game was very good. The people in charge of the activity described the players' attitudes as concentrated and very participative in both methods. The observers also found that players were having fun while playing the traditional game and the iPhone game. These results would support the ones obtained in the satisfaction test where the satisfaction variable scores were high (3.37 and 3.33 of a total of 4 for the iPhone and traditional method, respectively) and no significant differences were found between the iPhone and the traditional method. With regard to the cooperation between the players, the observers perceived a difference between the traditional game and the iPhone game. They perceived that players collaborated more in the iPhone method than in the traditional method. The average score given by the observers to the iPhone method was $8.17 \pm 1.04$ and $6.82 \pm 2.75$ to the traditional game. The observers commented that a great majority of players collaborated to find the objects requested by the guide character in the iPhone game. However, the players cooperated only in a few of the minigames in the traditional game.

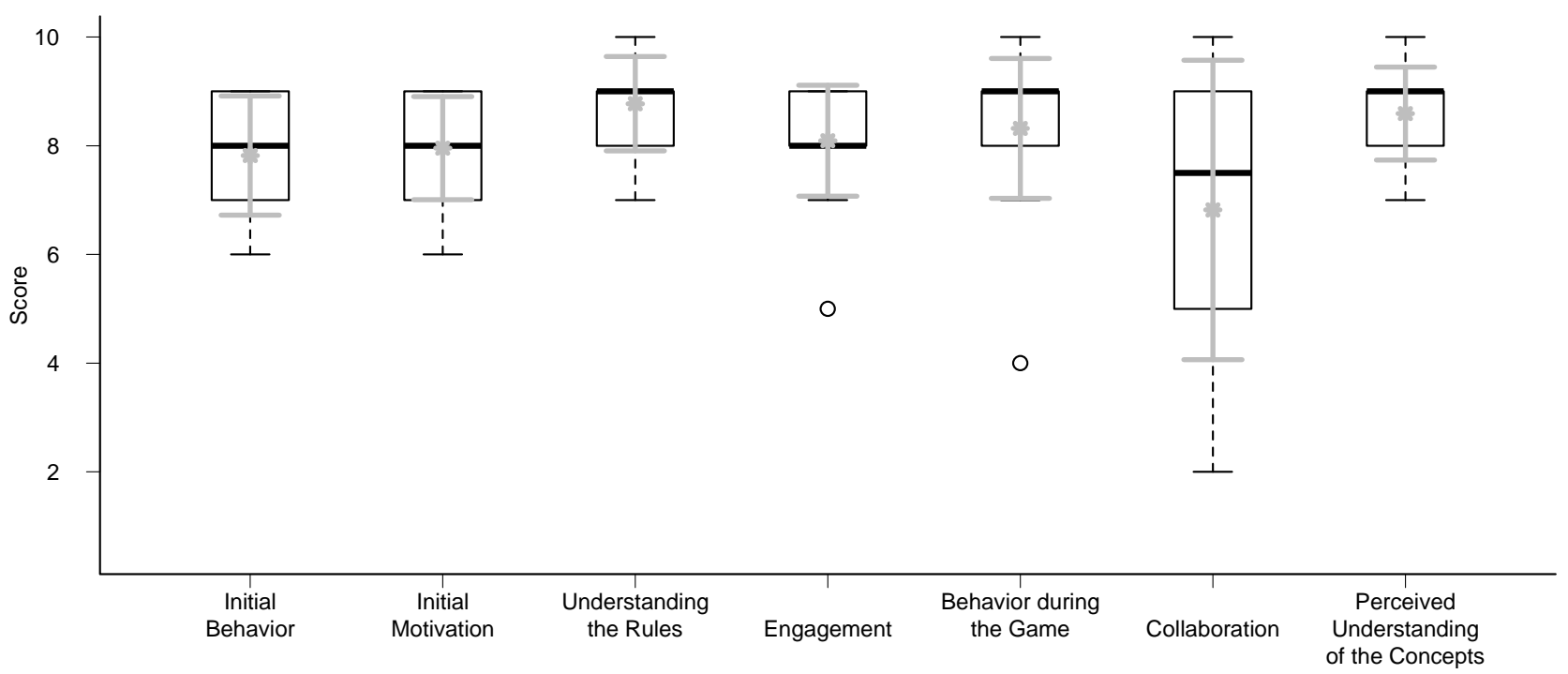

Fig. 17. Boxplots of the different aspects analyzed in the Traditional method by the people observing the players. The mean and standard deviation are represented with solid gray lines.

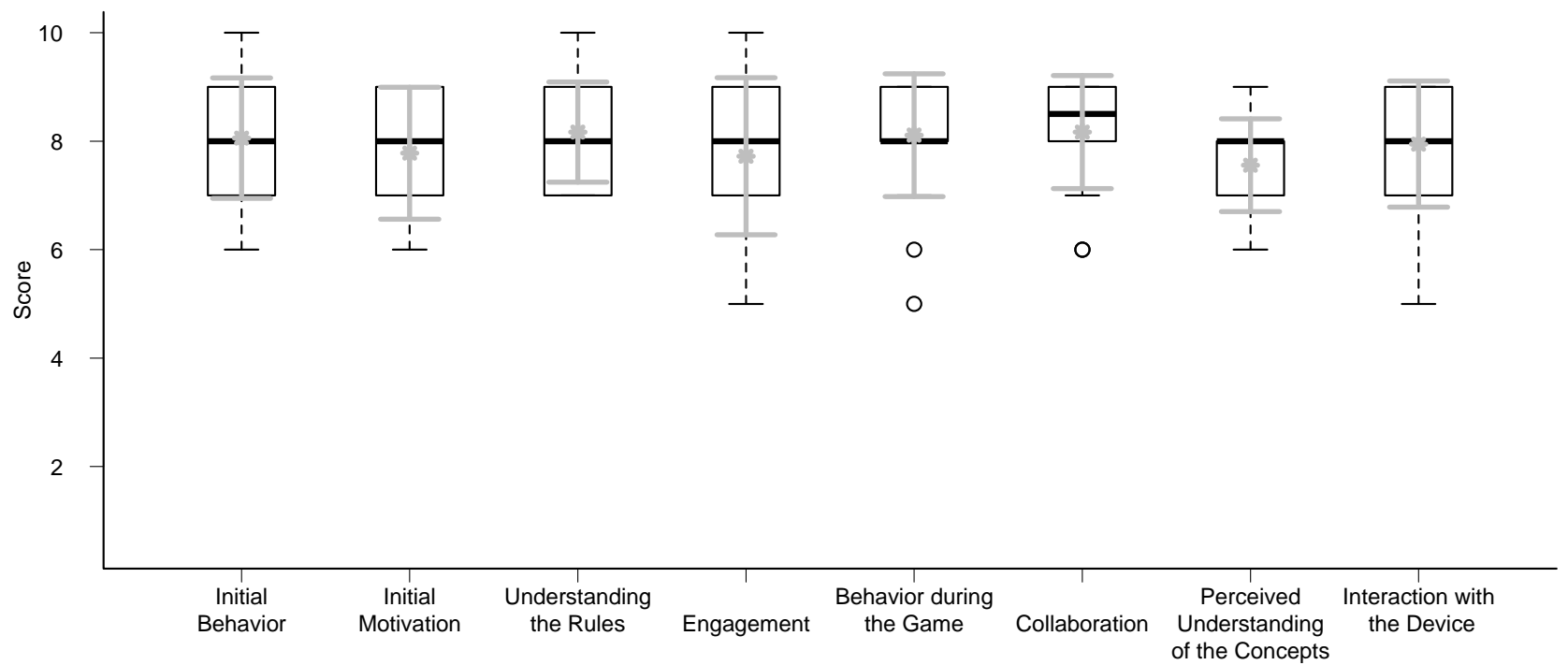

Fig. 18. Boxplots of the different aspects analyzed in the iPhone method by the people observing the players. The mean and standard deviation are represented with solid gray lines. 


\section{Discussion}

As argued by some authors (e.g. de Freitas, 2008; Egenfeldt-Nielsen, 2006), educational games have great potential for contributing to effective learning. However, there is not much empirical evidence of this potential. Moreover, several important issues have not usually been considered in the design and development of educational computer games. From our point of view, which is shared with previous suggestions, it is important to use a pedagogical foundation in order to design educational computer games (Lai-Chong Law et al., 2008). It is also very important to use a control group to evaluate learning outcomes (e.g. Egenfeldt-Nielsen, 2006; Harrington, 2006). As discussed in Section 4.4, we used a control group in our study. As explained in Section 3.1, the experiential learning theory of Kolb (1984), and Gardner's theory of multiple intelligences (1983) were used in the design of our game. Other works have pointed out the importance of considering national curricula in the development of educational computer games (de Freitas \& Oliver, 2006; Lai-Chong Law et al., 2008). We have taken the Spanish national curricula into account to design our game.

\subsection{Preliminary study}

We have presented a study $(n=150)$ to determine the subject preferences for educational computer games. With this preliminary study, we have attempted to cover the gap in research about the subjects and type of game that professionals consider most appropriate to be taught using computer games. To our knowledge, this is the first study in which the preferences of professionals have been studied. We consider this study to be valuable and useful not only for our country, but also for researchers in other countries.

\section{2. iPhone game and Augmented Reality}

We have developed an iPhone game based on the results of our preliminary study in accordance with two learning theories, the objectives and competences of the Spanish law for primary education, and several design principles. The game includes AR and several interaction forms (physical manipulation, touch-screen interaction, and accelerometer). To our knowledge, this is the first game that combines all these features. The iPhone game not only uses AR, but it makes AR an important part of the game. A great majority of the participants (91\%) would like to use AR in the classroom as a learning tool. This result would be an indicator that the AR technology in conjunction with the digital game motivated the children. Other results from our study that confirm this are the $96 \%$ of children that indicated that they would like to play with the iPhone game again and the $90 \%$ of children that preferred playing with the iPhone game over playing with the traditional game. Furthermore, the people observing the children during the activities commented that the players were motivated and engaged while they were playing the iPhone game.

Comparing these results to previous research where AR was not used, it can be observed that, in the study carried out by Ruchter, Klar and Geiger, (2010), the digital application did not improve motivation in children. However, in experiments like the one performed by Rosas et al., (2003) or Yang (2012), it can be observed that they obtained similar results to our study, but not as high as ours. This would indicate that AR technology could have been a factor that improved the motivation and engagement of the children in our study. From our point of view, the inclusion of AR in educational games could help in several ways because, apart from motivating the children, it would allow them to explore what they are learning from a variety of different perspectives (Kerawalla et al., 2006). Of course, AR cannot be used for everything, but its combination with other technologies opens up new possibilities. 


\subsection{The net generation}

In this study, we have tried to determine whether or not our participants follow the same trend regarding the use of electronic games as children of other countries. Children and adolescents are accustomed to playing electronic games daily, and this is a worldwide trend (Jaruratanasirikul, Wongwaitaweewong, \& Sangsupawanich, 2009). A study in the United States reported that $65 \%$ of children aged 4-11 played with large-screens about $2 \mathrm{~h}$ per day (Anderson et al.,2008). Diepenmaat et al. (2006) showed that more than $23 \%$ of 3500 Dutch children used computers for more than $3 \mathrm{~h}$ per day. Jaruratanasirikul et al. (2009) found that $64 \%$ of 1492 Thai students in the 7 th to 12 th grades played electronic games. A study in Hong Kong showed that adolescents $(n=2100)$ used the computer daily with a mean duration of over $2 \mathrm{~h}$ (Ho and Lee, 2001). Another study in Hong Kong reported the common use of several game devices (3-5 types), with about $40 \%$ of the children being weekly users and $18 \%$ being daily users among 476 students in a local primary school, aged 8-13 (Lui et al., 2011). Our study demonstrates that $14 \%$ of our participants are accustomed to playing electronic games daily, $30 \%$ of them are used to playing nearly every day, and 38\% are weekly users. Even though a larger sample may be required, our study suggests that Spanish children seem to follow the same trend regarding the use of electronic games as children in other countries.

\subsection{Learning outcomes}

Several authors have pointed out that there is still a lack of research that addresses the issue of how computer games enhance learning outcomes (e.g. Lee, Wong \& Fung (2010). According to Lee, Wong \& Fung (2010), "knowledge and capability cannot be directly measured". Alavi \& Leidner (2001) argued that only the action and performance resulting from learning can be observed and measured. Sharda et al. (2004) established a classification for learning outcomes with three groups: 1) Psychomotor outcomes, which include accuracy, efficiency, and response magnitude; 2) Cognitive outcomes, which include knowledge, comprehension, application, and analysis; and 3) Affective outcomes, which include attitude, students' perception of satisfaction, and appreciation for the learning experience.

A study was carried out for the cognitive outcomes to determine whether children learn more by playing the iPhone game than by playing a traditional game. No statistically significant differences were found between the learning outcomes of playing the iPhone game or playing the traditional game. This result corroborates our primary hypothesis ("There would not be significant differences between playing with the iPhone game or the traditional game regarding learning results"). Nevertheless, the children had a high level of learning (with approximately $70 \%$ of correct answers) in both games. On the other hand, when the perception of the people in charge of the study is considered, they perceived that the children understood the concepts better when using the traditional method. Despite of this, the scores were quite high in the iPhone and traditional methods. One possible explanation for this perception is that this score is intrinsically related to their participation in the game (explaining the game, transmitting knowledge, etc. in the traditional method), so it may be slightly biased towards the traditional method. However, the observers commented that the players were paying attention to the explanations given by the iPhone game or the person guiding the traditional game. Taking into account all these data, from our point of view, the game context and the game itself could have been powerful transmitters of knowledge. This implies that the children have achieved similar knowledge improvements using an autonomous game (iPhone game) as using a custom and guided game (traditional game). This is an encouraging result because children can learn not only in the classroom, but also anywhere and any time without requiring full control over their learning process.

When we compare our results to other studies, there is a similar trend (no statistical significant differences can be observed). However, unfortunately none of the papers indicate the percentage of correct answers. If this percentage were available, a more complete comparison would be possible. It is important to note that none of the studies reviewed used AR or learning theories when designing their games. The research performed by Ebner and Holzinger (2007), Telner et al. (2010), and Yang (2012) 
showed that the people who played the computer games achieved the same results with regard to the acquired knowledge as the people who used the traditional approaches. If we compare our results to others that use mobile learning games, such as Rosas et al. (2003), we also observe similar results since no significant differences were found in that study regarding the learning outcomes between the experimental group and the internal control group. Despite having similar results to ours, it must be taken into account that the studies by other authors have compared their new methods using games with traditional classroom lessons, whereas in our study we compared our new method (AR and iPhone) with a traditional game. Games (traditional or digital) can promote student motivation (Papastergiou, 2009) and improve the learning experience of the participants (Connolly, Stansfield, and Hainey, 2007). This motivation is usually not present in traditional lessons. Moreover, in the other studies, the participants had an initial lecture where all the concepts were explained. All the participants, regardless of the group they belonged to (control or experimental) played under the same conditions. They could ask questions in the lecture class, but not when playing the game. In our case, there was no initial lecture. Instead, the concepts were explained by the iPhone game or the people in charge of the traditional game. The children could ask questions during the traditional game to better understand the concepts explained. This could not be done in the iPhone game. While, a priori, these two factors would favor the learning outcomes of the traditional game, the results showed no significant differences. We think that the fact that there were no significant differences between the two methods was a good result because it might mean that the use of AR technology helped to counteract the advantage children had in the traditional game and improved their learning experience.

For the affective outcomes, $100 \%$ of participants playing with the iPhone game thought they had learned using this device. On the other hand, one of the principal assets of games when compared to other educational programs is likeability and the resulting motivation for students. Motivation has always been an important issue in educational programs. Several aspects of motivation have been examined such as motivational diagnosis (de Vincente \& Pain, 2002) or instructional planning to increase motivation (Matsubara \& Nagamachi, 1996). Price et al. (2003) and Virvou \& Katsionis (2008) used a similar approach to evaluate likeability. In the Price et al. (2003) game, an important clue for the assessment of excitement and engagement of players was their desire to continue interacting and playing. In our case, $96 \%$ of children indicated that they would like to play with the iPhone game again. With regard to the children's preferences, $90 \%$ preferred the experience with the iPhone game to traditional play.

\subsection{Usability}

Several authors have considered usability or perceived ease of use as an important technical factor that affects educational effectiveness (Jones et al., 1999; Mayes \& Fowler, 1999; Squires, 1999). Davis (1989) theorizes the accepted Technology Acceptance Model (TAM), which considers two perceptions (perceived usefulness, PU, and perceived ease of use, PEOU) to determine a person's intention to use a technology. According to Davis (1989, p. 322), items such as "important", "relevant", "useful" and "valuable" correspond to PU, while items such as "convenient", "controllable", "easy", and "unburdensome" correspond to PEOU. In our study, PU was measured indirectly using a survey adapted to the age of the children, in which the children where asked if they would like to use the AR system at school. Their answers positively indicated their enthusiasm for the AR system. The PEOU was directly measured in the survey and also indicated a high degree of acceptance of the AR technology by the children. According to Sun et al., (2008), learning systems that are easy to use help students to focus their attention on the learning content, and they are more motivated to learn. In our case, the iPhone game was easy to manipulate for $97 \%$ of the participants. In addition, the people observing the players during the game stated that a great majority of players did not have problems interacting with the device. Thus, according to the above-mentioned suggestions, our iPhone game does help students focus their attention on the learning content. 


\section{Conclusions}

We have presented a study to determine the subject preferences for educational computer games for children. In our opinion, it is a valuable study that can help other researchers choose the subject and type of their games. It can also be used to compare these preferences with students from other countries. Our net study suggests that Spanish children seem to follow the same trend regarding the use of electronic games that children in other countries do.

We have developed an iPhone game for transmitting knowledge as part of multiculturalism, solidarity and tolerance following the study about subject preferences, established learning theories, several design principles, and the objectives and competences of the Spanish law for primary education. The iPhone game includes multiple interaction forms (touch-screen interaction and accelerometer) and combined AR mini-games with non-AR mini-games. To our knowledge, this is the first work with all these features. Although the results have been satisfactory, we have not yet checked the contribution of each feature to this success. The results indicate that the children achieved similar knowledge improvements using an autonomous game (iPhone game) as when using a custom and guided game (traditional game). This is an encouraging result. This type of learning opens up new opportunities for educators because the learning activity is not limited to the classroom; it can also be completed anywhere and any time, without requiring strict supervision by the teacher. This type of games only needs a minimum setup with some markers printed on paper and the handheld device. Considering the increasing use of technological devices among young people, in our opinion, games of this type have great potential as pervasive educational games.

Moreover, a very high percentage of the participants (91\%) would like to use AR in the classroom as a learning tool. This is a very encouraging result. However, more studies should be carried out to determine the benefits or problems with this type of technology. The labyrinth game that used the accelerometer was the preferred game. The person in charge of the activity also corroborated the children's preference for the accelerometer. In our opinion, this type of interaction is very promising for educational games. However, more specific studies should be carried out to corroborate this preference, as well as its speed and accuracy for different activities.

Our research has allowed us to draw conclusions about the different components in the design of the game, in accordance with Garris, Ahlers \& Driscoll (2002). These are related to the following:

1) Contents applied to school curriculum.

2) Student motivation that is intrinsic to the game situation: Factors that make an activity intrinsically motivating are challenge, curiosity, etc. (Some educational games have lost this fun element).

3) A cycle is triggered that includes fun, reflection, etc. encouraging users to learn specific contents thereby improving the feedback in the learning process.

For future work, we would like to use the iPhone for evaluation. This would be a very useful option that could provide feedback to both students and teachers. We also hope to carry out more quantitative and qualitative evaluations at different schools to produce further empirical evidence associated with the game. As stated in section 3.1, our game focuses on transmitting knowledge as part of multiculturalism, solidarity, and tolerance. However, a very interesting future work could be to improve the game by addressing more specific aspects and evaluating them, paying special attention to assessing whether or not the game promotes the values transmitted. Our study is centered on determining whether or not children acquire knowledge in the short-term, thus, a possible future work would be to check long-term learning. Another possible study is to compare a paper-based evaluation with an evaluation using the same tool as used for learning (in our case, the iPhone game). This study would be in line with other works that have compared paper-based evaluation with computer-based methods (McDonald, 2002). The game itself could be enhanced in several aspects, like adding other play modes such as multiplayer. With the multiplayer mode, we could make collaborative and competitive gameplay. Another challenge could be to make the game less linear and predictable, which would make the game more replayable. Making the game more customizable could improve the 
experience; for example, adapting the game difficulty to low-, mid- and high-grade students. Another aspect to consider is to allow the teachers to be more involved; for example, letting them establish the game difficulty taking the level of the student into account. With the appearance of new handheld devices, a device with a larger screen could also be used for comparison, or even an autostereoscopic display (e.g. Nintendo 3DS or LG Optimus 3D). Finally, considering the continuous and exponential improvement of mobile devices, more adequate educational games could be developed to improve their learning effectiveness.

\section{Acknowledgments:}

- This work was funded by the Spanish APRENDRA project (TIN2009-14319-C02).

- We would like to thank the following for their contributions:

- The "Escola d'Estiu" and especially Juan Cano, Miguelón Giménez, and Javier Irimia. This work would not have been possible without their collaboration.

- Sonia Torres and Jessica Janer Marti for their help during the testing phase.

- Encarna Torres, Severino González, M. José Vicent, Patricia Limiñana, Tamara Aguilar, Alfonso López, Yolanda Martínez, Enrique Daunis, M. José Martínez, and Eloy Hurtado for their help.

- The professionals who participated in the preliminary study.

- The children's parents who signed the agreement to allow their children to participate in the second study.

- The children who participated in the second study.

- The ETSInf for letting us use its facilities during the testing phase.

\section{References}

Alavi, M., \& Leidner, D. E. (2001). Research commentary: technology-mediated learning - a call for greater depth and breadth of research. Information Systems Research, 12(1), 1-10.

Anderson, S. E., Economos, C. D., \& Must, A. (2008). Active play and screen time in US children aged 4 to 11 years in relation to socio-demographic and weight status characteristics: a nationally representative cross-sectional analysis. BMC Public Health, 8, 366-372.

Ardito, C., Costabile, M.F., Lanzilotti, R., Pederson, T. (2007). Making dead history come alive through mobile game-play, Conference on Human Factors in Computing Systems, 2249-2254.

Azuma, R. T. (1997). A Survey of Augmented Reality. Media 6(4), 355-385.

Beck, J. C., \& Wade, M. (2004). Got game: How the gamer generation is reshaping business forever. Boston: Harvard Business School Press.

Beck, J. C., \& Wade, M. (2006). The kids are alright: How the gamer generation is changing the workplace. Boston: Harvard Business School Press.

Bekebrede, G, Warmelink, H.J.G., \& Mayer, I.S.(2011). Reviewing the need for gaming in education to accommodate the net generation, Computers \& Education, 57: 1521-1529

Bimber, O., Fröhlich, D., Schmalstieg, D., \& Encarnaçao, L.M. (2001). The virtual Showcase, IEEE Computer Graphics \& Applications, 21 (6), 48-55.

Brumels, K. A., Blasius, T., Cortright, T., Oumedian, D., \& Solberg, B. (2008). Comparison of efficacy between traditional and video game based balance programs. Clinical Kinesiology Journal of the American Kinesiotherapy Association. 62 (4), 26-31.

Burgos, D., Nimwegen, C.V., Oostendorp, H.V., Koper, R. (2007). Game-based learning and the role of feedback: a case study, Advanced Technology for Learning, 4 (4), 188-193.

Butler, M. (2011). Android: Changing the Mobile Landscape. IEEE Pervasive Computing, 10(1), 4-7.

Chen C.-M., Tsai Y.-N. (2012). Interactive augmented reality system for enhancing library instruction in elementary schools. Computers \& Education, 59(2), 638-652. 
Connolly, T. M., Stansfield, M. H., \& Hainey, T. (2007). An application of games-based learning within software engineering. British Journal of Educational Technology, 38(3), 416-428.

Csikszentmihalyi, M. (1990). Flow: The psychology of optimal experience. New York: Harper and Row.

Davis, F. D. (1989). Perceived usefulness, perceived ease of use, and user acceptance of information technology. MIS Quarterly, 13(3), 319-340.

de Freitas, S. (2006). Learning in immersive worlds. Joint Information Systems Committee.

de Freitas, S., \& Oliver, M. (2006). How can exploratory learning with games and simulations within the curriculum be most effectively evaluated? Computers \& Education, 46, 249-264.

de Freitas, S. (2008). Serious virtual worlds. A scoping study. Prepared for the JISC e-learning programme. $<$ http://www.jisc.ac.uk/media/documents/publications/seriousvirtualworldsv1.pdf $>$.

de Vincente, A., \& Pain, H. (2002). Informing the detection of the students' motivational state: An empirical study. Intelligent Tutoring Systems 2002, LNCS, 2363, 932-943.

Dickey. M.D. (2005). Engaging By Design: How Engagement Strategies in Popular Computer and Video Games Can Inform Instructional Design. Education Technology Research \& Development, 53(2): 67-83.

Diepenmaat, A. C. M., van der Wal, M. F., de Vet, H. C. W., \& Hirasing, R. A. (2006). Neck/shoulder, low back, and arm pain in relation to computer use, physical activity, stress, and depression among Dutch adolescents. Pediatrics, 117, 412-416.

Diverdi, S., Nurmi, D., \& Hollerer. T. (2003). A framework for generic interapplication interaction for 3D AR environments. Augmented Reality Toolkit Workshop 2003, IEEE Computer Society, pp. 8693.

Ebner, M., \& Holzinger, A. (2007). Successful implementation of user-centered game based learning in higher education: An example from civil engineering. Computers \& Education, 49(3), 873-890.

Egenfeldt-Nielsen, S. (2006). Overview of research on educational games. Digital Kompetanse, 1(3), 184-213.

Fjeld, M., Fredriksson, J., Ejdestig, M., Duca, F., Bötschi, K., Voegtli, B.M., et al. (2007). Tangible User Interface for Chemistry Education: Comparative Evaluation and Re-Design, CHI 2007, 805808.

Gardner, H. (1983). Frames of mind: The theory of multiple intelligences. New York: Basic.

Garris, R., Ahlers, R., Driskell, J.E. (2002). Games, motivation, and learning: A research and practice model. Simulation \& Gaming. 33 (4), 441-467.

GATE. (2011). Project information. GATE j Game Research for Training and Entertainment. Retrieved February 7, 2011, from. http://gate.gameresearch.nl/index.php?page=85.

Graft, K. (2009). Analyst: iPhone To Drive Mobile Game Market Sales To \$11.7 Billion By 2014. Retrieved April, 21st, 2012, from http://gamasutra.com/php-bin/news_index.php?story=25766.

Godwin, L., \& Kaplan, S. (2008). Designing ee-Learning Environments: Lessons from an Online Workshop. Innovate: Journal of Online Education, 4(4).

Harrington, M. C. R. (2006). Situational learning in real and virtual space: Lessons learned and future directions. Proceedings ACM SIGGRAPH.

Hainey T., Connolly T.M., Stansfield M., Boyle E.A. (2011). Evaluation of a game to teach requirements collection and analysis in software engineering at tertiary education level. Computers \& Education, 56(1), 21-35.

Hanratty, B., \& Taggart, D. (2005). The Pushkin Trust: experiential learning and children with special educational needs. An investigation. Irish Educational Studies, 24(2-3), 243-252.

Healey, M., \& Jenkins, A. (2000). Kolb's Experiential Learning Theory and Its Application in Geography in Higher Education. Journal of Geography, 99(5), 185-195.

Henrysson, A., \& Billinghurst, M. (2007). Using a mobile phone for 6 DOF mesh editing. The 7th ACM SIGCHI New Zealand Chapter's international Conference on Computer-Human interaction: Design Centered HCI (CHINZ '07), 254: 9 - 16. 
Herrington, A., Herrington, J., \& Mantei, J. Design principles for mobile learning 2009, http://ro.uow.edu.au/edupapers/ 88

Ho, S., \& Lee, T. (2001). Computer usage and its relationship with adolescent lifestyle in Hong Kong. Journal of Adolescent Health, 29, 258-266.

Jaruratanasirikul, S., Wongwaitaweewong, K., \& Sangsupawanich, P. (2009). Electronic game play and school performance of adolescents in Southern Thailand Somchit. Cyberpsychology \& Behavior, 12(5), 509-512.

Jones, V., \& Jo, H. J. (2004). Ubiquitous learning environment: an adaptive teaching system using ubiquitous technology. In Proceedings of the 21st ASCILITE conference (pp. 468-474), Perth, Western Australia, 5-8 December, 2004.

Jones, A., Scanlon, E., Tosunoglu, C., Morris, E., Ross, S., Butcher, P., et al. (1999). Contexts for evaluating educational software. Interacting with Computers, 11(5), 499-516.

Juan. M.C., Beatrice, F., \& Cano, J. 2008. Augmented Reality for learning the interior of the Human Body, In Proceedings of the IEEE International Conference on Advanced Learning Technologies Learning technologies in the Information society (ICALT'08), 186-188.

Juan. M. C., Toffetti, G., Abad, F., \& Cano, J. 2010. Tangible cubes used as the user interface in an augmented reality game for edutainment, In Proceedings of the IEEE International Conference on Advanced Learning Technologies Learning technologies in the Information society (ICALT'10), 599-603.

Juan, M. C., Carrizo, M., Giménez, M., \& Abad, F. (2011a). Using an augmented reality game to find matching pairs, In Proceedings of the $19^{\text {th }}$ International Conference on Computer Graphics, Visualization and Computer Vision, 59-66, http://wscg.zcu.cz/WSCG2011/!_2011_WSCGShort_Papers.pdf

Juan, M.C., Furio, D., Alem, L., Ashworth, P., \& Cano, J. (2011b). ARGreenet and BasicGreenet: Two mobile games for learning how to recycle, $19^{\text {th }}$ International Conference on Computer Graphics, Visualization and Computer Vision'2011, 25-32, http://wscg.zcu.cz/WSCG2011/!_2011_WSCG_Full_papers.pdf

Karpischek, S., Marforio, C., Godenzi, M., Heuel, S., \& Michahelles, F. (2009). Mobile augmented reality to identify mountains, In Adjunct Proceedings of the 3rd European Conference on Ambient Intelligence (AmI-09), http://www.im.ethz.ch/people/karpischek/ami09_peaks_cr_20091024_sk.pdf

Kaufmann, H. (2004). Geometry Education with Augmented Reality, PhD Dissertation thesis, Vienna University of Technology.

Kato, H., Billinghurst, M., Poupyrev, I., Tetsutani, T., \& Tachibana, K. (2001). Tangible Augmented Reality for Human Computer Interaction. The 17th Nicograph (in japanese), pp. 39-44.

Kebritchi, M., \& Hirumi, A. (2008). Examining the pedagogical foundations of modern educational computer games. Computers \& Education, 51, 1729-1743

Kerawalla, L., Luckin, R., Seljeflot, S., Woolard, A. (2006). "Making it real”: exploring the potential of augmented reality for teaching primary school science. Virtual Real. 10 (3), 163-174.

Kezar, A. (2001). Theory of Multiple Intelligences: Implications for Higher Education. Innovative Higher Education, 26(2), 141-154.

Koh, R.K.C., Duh, H.B.L., \& Gu, J. (2010). An integrated design flow in user interface and interaction for enhancing mobile AR gaming experiences, IEEE International Symposium On Mixed and Augmented Reality (ISMAR'10), pp. 47 - 52.

Kolb, D. A. (1984). Experiential learning: Experience as a source of learning and development. Englewood Cliffs, NJ: Prentice-Hall.

Krevelen, D.W.F.V, \& Poelman, R. (2010). A Survey of Augmented Reality Technologies, Applications and Limitations. International Journal 9(2), 1-20. 
Lai-Chong Law, E., Kickmeier, D. A., \& Holzinger, A. (2008). Challenges in the development and evaluation of immersive digital educational games. Lecture Notes in Computer Science, 5298, 1930.

Larsen, L.B. Jensen, R.B., Jensen, K.L., \& Larsen, S. (2005). Development of an automatic pool trainer, Conference on Advances in Computer Entertainment Technology (ACE'05), 83-87.

Lavín-Mera, P., Moreno-Ger, P., \& Fernández-Manjón, B. (2008). Development of Educational Videogames in m-Learning Contexts. In Proceedings of the 2008 Second IEEE International Conference on Digital Game and Intelligent Toy Enhanced Learning (DIGITEL'08), 44-51.

Lee, E. A-L., Wong K. W., \& Fung, C. C. (2010). How does desktop virtual reality enhance learning outcomes? A structural equation modeling approach, Computers \& Education, 55, 1424-1442

Leemkuil, H. (2005). Is it all in the game? Learner support in an educational knowledge management simulation game. Unpublished doctoral thesis. Enschede, The Netherlands: University of Twente.

Lewin, C. (1995). Test Driving CARS: Addressing the Issues in the Evaluation of Computer Assisted Reading Software. Proceedings of International Conference on Computers in Education, 452-459.

Lui, D.P.Y., Szeto, G.P.Y., \& Jones, A.Y.M. (2011). The pattern of electronic game use and related bodily discomfort in Hong Kong primary school children. Computers \& Education, 57, 1665-1674

Matsubara, Y., \& Nagamachi, Y. (1996). Motivation system and human model for intelligent tutoring. 3rd International Conference on ITSs, 139-147.

Mayer, I., Stegers-Jager, K., \& Bekebrede, G. (2007). Spelend leren in virtuele werelden. Bouwstenen voor online gaming in het hoger onderwijs. Groningen: Wolters-Noordhoff.

Mayes, J. T., \& Fowler, C. J. (1999). Learning technology and usability: A framework for understanding courseware. Interacting with Computers, 11(5), 485-497.

McDonald, A.S. (2002). The impact of individual differences on the equivalence of computer-based and paper-and-pencil educational assessments, Computers \& Education, 39(3), 299-312.

McFarlane, A., Sparrowhawk, A., \& Heald, Y. (2002). Report on the educational use of games. www.teem.org.uk/publications/teem_gamesined_full.pdf.

Milgram, P., \& Kishino, F. (1994). A taxonomy of mixed reality visual displays. IEICE Transactions on Information Systems, E77-D(12), 1-15.

Motiwalla, L. (2007). Mobile learning: A framework and evaluation. Computers \& Education, 49(3), 581-596.

O’Neil, H. F., Wainess, R., \& Baker, E. L. (December 2005). Classification of learning outcomes: evidence from the computer games literature. The Curriculum Journal, 16(4).

O'Shea, P., Dede, C., Mitchell, R., \& Johnston, C. (2009). Lessons learned about designing augmented realities, International Journal of Gaming and Computer-Mediated Simulations. 1(1): 1-15.

Papastergiou, M. (2009). Digital Game-Based Learning in high school Computer Science education: Impact on educational effectiveness and student motivation. Computers \& Education, 52(1), 1-12.

Prensky, M. (2001a). Digital game-based learning. New York: McGraw-Hill.

Price, S., Rogers, Y., Scaife, M., Stanton, D., \& Neale, H. (2003). Using tangibles to promote novel forms of playful learning. Interacting with Computers, 15, 169-185.

Programmabureau Maatschappelijke Sectoren \& ICT. (2011). Projecten onderwijs. Programmabureau M\&ICT. Retrieved February 7, 2011, from. http://www.mict.nl/index.php?option $=$ com_content\&task $=$ category\&sectionid=27\&id=55\&Itemid $=212$.

Randel, J.M., B.A. Morris, C.D. Wetzel, and B.V. Whitehill. (1992). The Effectiveness of Games for Educational Purposes: A Review of Recent Research. Simulation \& Gaming, 23: 261-276.

Reese, A. C., \& College, M. (1998). Implications Of Results From Cognitive Science Research For Medical Education. Medical Education, 1-9.

Robertson, J., \& Howells, C. (2008). Computer game design: Opportunities for successful learning. Computers \& Education, 50, 559-578. 
Rosas R., Nussbaum M., Cumsille P., Marianov V., Correa M., Flores P., Grau V., Lagos F., López X., López V., Rodriguez P., Salinas M. (2003). Beyond Nintendo: design and assessment of educational video games for first and second grade students. Computers \& Education, 40(1), 71-94.

Rosler, A. (2009). Augmented Reality Games on the iPhone. (Bachelor thesis, Blekinge Institute of Technology, 2009). Retrieved from: http://amandarosler.com/Amanda_Rosler_Augmented_Reality_Games_on_the_iPhone.pdf

Ruchter M., Klar B., Geiger W. (2010). Comparing the effects of mobile computers and traditional approaches in environmental education. Computers \& Education, 54(4), 1054-1067.

Sandor, C., \& Klinker, G. (2005). A rapid prototyping software infrastructure for user interfaces in ubiquitous augmented reality. Personal Ubiquitous Computing. 9(3): 169-185.

Shaffer, D.W., Squire, K. T., Halverson, R., \& Gee, J. P. (2004). Video games and the future of learning. Phi Delta Kappan . http://www.academiccolab.org/resources/gappspaper1.pdf.

Sharda, R., Romano, N. C., Jr., Lucca, J. A., Weiser, M., Scheets, G., Chung, J. M., et al. (2004). Foundation for the study of computer-supported collaborative learning requiring immersive presence. Journal of Management Information Systems, 20(4), 31-63.

Sharples, M., Corlett, D., \& Westmancott, O. (2002). The design and implementation of a mobile learning resource. Personal and Ubiquitous Computing, 6(3), 220-234.

Shelton, B.E., \& Hedley, N.R. (2002). Using Augmented Reality for Teaching earth-sun relationships to undergraduate geography students, $1^{\text {st }}$ IEEE International Augmented Reality Toolkit Workshop, 8 pag., http://depts.washington.edu/pettt/papers/ shelton-hedley-art02.pdf.

Shelton, B. E., \& Hedley, N. R. (2004). Exploring a cognitive basis for learning spatial relationships with augmented reality. Technology, Instruction, Cognition and Learning, 1(4), 323-357.

Squire, K. (2002). Cultural framing of computer/video games. Game Studies, 2(1). http://www.gamestudies.org/0102/squire.

Squires, D. (1999). Editorial. Usability and educational software design: Special issue of interacting with computers. Interacting with Computers, 11(5), 463-466.

Sun, P.-C., Tsai, R. J., Finger, G., Chen, Y.-Y., \& Yeh, D. (2008). What drives a successful eLearning? An empirical investigation of the critical factors influencing learner satisfaction. Computers \& Education, 50(4), 1183-1202.

Tapscott, D. (1998). Growing up digital. The rise of the net generation. New York: McGraw-Hill.

Telner, D., Bujas-Bobanovic, M., Chan, D., Chester, B., Marlow, B., Meuser, J., Rothman, A., et al. (2010). Game-based versus traditional case-based learning: comparing effectiveness in stroke continuing medical education. Canadian family physician Medecin de famille canadien, 56(9), e345-e351.

Vernadakis N., Gioftsidou A., Antoniou P., Ioannidis D., Giannousi M. (2012). The impact of Nintendo Wii to physical education students' balance compared to the traditional approaches. Computers \& Education, 59(2), 196-205.

Virvou, M., \& Alepis, E. (2005). Mobile educational features in authoring tools for personalized tutoring. Computers \& Education, 44, 53-68.

Virvou, M., \& Katsionis, G. (2008). On the usability and likeability of virtual reality games for education: The case of VR-ENGAGE. Computers \& Education, 50, 154-178

Vitzthum. A. (2006). SSIML/AR: A Visual Language for the Abstract Specification of Augmented Reality User Interfaces, IEEE Symposium on 3D User Interfaces, pp. 135- 142.

Vygotsky, L. S. (1978) Mind in Society: The development of higher psychological process. Cambridge, MA: Harvard University Press.

Wang, K, Chen, L., Chu, P., \& Cheng, Y. (2009). A study on the design of Augmented Reality user interfaces for mobile learning systems in heritage temples, Virtual and Mixed Reality, LNCS, 5622: 282-290. 
Warmelink, H., \& Mayer, I. (Eds.). (2009). Learning in a virtual world. Reflections on the cyberdam research and development project. Nijmegen: Wolf Legal Publishers.

West, J., \& Mace, M. (2010). Browsing as the killer app: Explaining the rapid success of Apple's iPhone. Telecommunications Policy, 34(5-6), 270-286.

Wood, D., Underwood, J., Avis, P. (1999). Integrated learning systems in the classroom, Computers \& Education, 33 (2-3), 91-108.

Woods, E., Billinghurst, M., Looser, J., Aldridge, G., Brown, D., Garrie, B., \& Nelles, C. (2004). Augmenting the science centre and museum experience, GRAPHITE, 230-236.

Yang, Y.-T.C. (2012). Building virtual cities, inspiring intelligent citizens: Digital games for developing students' problem solving and learning motivation. Computers \& Education, 59(2), 365377.

Zhang, P., Carey, J., Te'eni, D., and Tremaine, M. (2005). Integrating Human-Computer Interaction Development into the Systems Development Life Cycle: A Methodology. Communications of the Association for Information Systems. 15 (29), 512-543.

Zhou, F., Duh, H.B.L., \& Billinghurst, M. (2008). Trends in augmented reality tracking, interaction and display: A review of ten years of ISMAR, 7th IEEE/ACM International Symposium on Mixed and Augmented Reality (ISMAR'08), pp.193-202. 